Florida International University

FIU Digital Commons

3-6-2020

\title{
Longitudinal Association between Video Game Use and Physical, Mental, and Social Health Outcomes in Young Adults in the United States
}

Ari D. Hozman

Florida International University, ahozm001@fiu.edu

Follow this and additional works at: https://digitalcommons.fiu.edu/etd

Part of the Public Health Commons

\section{Recommended Citation}

Hozman, Ari D., "Longitudinal Association between Video Game Use and Physical, Mental, and Social Health Outcomes in Young Adults in the United States" (2020). FIU Electronic Theses and Dissertations. 4376.

https://digitalcommons.fiu.edu/etd/4376

This work is brought to you for free and open access by the University Graduate School at FIU Digital Commons. It has been accepted for inclusion in FIU Electronic Theses and Dissertations by an authorized administrator of FIU Digital Commons. For more information, please contact dcc@fiu.edu. 


\section{FLORIDA INTERNATIONAL UNIVERSITY}

Miami, Florida

\section{LONGITUDINAL ASSOCIATION BETWEEN VIDEO GAME USE AND PHYSICAL, MENTAL, AND SOCIAL HEALTH OUTCOMES IN YOUNG ADULTS IN THE UNITED STATES}

A dissertation submitted in partial fulfillment of

the requirements for the degree of

DOCTOR OF PHILOSOPHY

in

PUBLIC HEALTH

by

Ari Daniel Hozman

2020 
To: Dean Tomás Guilarte

R. Stempel College of Public Health and Social Work

This dissertation, written by Ari Daniel Hozman, and entitled Longitudinal Association between Video Game Use and Physical, Mental, and Social Health Outcomes in Young Adults in the United States, having been approved in respect to style and intellectual content, is referred to you for judgement.

We have read this dissertation and recommend that it be approved.

Florence George

Mariana Sanchez

Virginia McCoy

Elena Bastida, Major Professor

Date of Defense: March 6, 2020

The dissertation of Ari Daniel Hozman is approved.

Dean Tomás R. Guilarte R. Stempel College of Public Health and Social Work

Andrés G. Gil

Vice President for Research and Economic Development and Dean of the University Graduate School

Florida International University, 2020 
(C) Copyright 2020 by Ari Daniel Hozman

All rights reserved. 


\section{DEDICATION}

This dissertation is dedicated to my mother, Diane Ruth Hozman, who passed away on July 10th, 2013. Her own academic achievements and occupation as a social worker inspired me to always continue with my education. She taught me what it means to be a "mensch", to always grow, mature, and continue to develop despite the many hardships of life. 


\section{ACKNOWLEDGMENTS}

I would like to thank the dissertation committee members for the countless hours they spent with me helping to develop and complete this dissertation.

My major professor, Dr. Elena Bastida, has always advocated on my behalf and been a great teacher and mentor to me throughout my doctoral studies at Florida International University. Her guidance, including with the dissertation, but also during my time as a graduate assistant and teaching assistant ensured my successful matriculation through the doctoral program in public health. Thanks to her efforts I was able to obtain the crucial experience needed to pursue a career as a professor.

Dr. Virginia McCoy, not only as a professor but also working under her as a graduate assistant, has always been an inspiration to me. She imparted upon me the tools I need to succeed as a professor, and I wish her the best into retirement. She will be missed in the department of Health Promotion and Disease Prevention.

Dr. Mariana Sanchez and Dr. Florence George for their guidance in conducting statistical analyses and the development of the dissertation.

Florida International University for providing funding throughout my doctoral studies as a graduate assistant and subsequently, a recipient of the Doctoral Year Fellowship award.

This research uses data from Add Health, a program project directed by Kathleen Mullan Harris and designed by J. Richard Udry, Peter S. Bearman, and Kathleen Mullan Harris at the University of North Carolina at Chapel Hill, and funded by grant P01HD31921 from the Eunice Kennedy Shriver National Institute of Child Health and Human Development, with cooperative funding from 23 other federal agencies and 
foundations. Information on how to obtain the Add Health data files is available on the Add Health website (http://www.cpc.unc.edu/addhealth). No direct support was received from grant P01-HD31921 for this analysis. 


\section{ABSTRACT OF THE DISSERTATION \\ LONGITUDINAL ASSOCIATION BETWEEN VIDEO GAME USE AND PHYSICAL, MENTAL, AND SOCIAL HEALTH OUTCOMES IN YOUNG ADULTS IN THE UNITED STATES}

by

Ari Daniel Hozman

Florida International University, 2020

Miami, Florida

Professor Elena Bastida, Major Professor

Background: Increasing adolescent engagement in video game use and its associations with public health outcomes has been a controversial topic over the last several decades, with studies conducted in the United States only managing to produce contradictory results. This dissertation explores the statistical associations between video game use in adolescents and various physical, mental and social health outcomes as they develop into adulthood in the United States.

Methodology: Secondary data analysis was conducted, guided by Life Course Theory, utilizing publicly available data from the National Longitudinal Study of Adolescent to Adult Health.

Results: Video game use during adolescence was significantly associated with the risk for development of metabolic syndrome in adulthood $(\mathrm{p}=.034)$. No significant association was found between video game use at any time point and increased measures of violence and aggression. A significant association was found between weekly hours of 
video game use and sleep problems $(\mathrm{p}=.002)$, depression $(\mathrm{p}=.006)$, anxiety / panic attacks $(\mathrm{p}=.021)$, and marijuana use $(\mathrm{p}=.001)$. No significant association was found between video game use and ADHD/ADD and drug use excluding marijuana.

Conclusion: This dissertation highlights several risks and benefits associated with engaging in video game use. These findings help to inform future public health practice and research. In moderation video game use was shown to have prosocial and positive effects on youth development as they grow into adulthood. However, when video game use exceeded 30 hours or more per week, detrimental effects began to emerge, including an increased risk for the development of metabolic syndrome, sleep problems, depression, anxiety, and marijuana use. Demographic variables such as gender and race / ethnicity and Life Course Theory variables of education and marital status were shown to have greater associations across all health outcomes than video game use at any time point. Recommendations for future research on the topic are discussed, including further investigation of the more significant findings and replication of the statistical analyses using Add Health wave V data once available. 


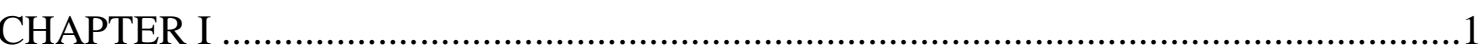

Introduction and Public Health Significance ………..................................................

Theoretical Framework..................................................................................

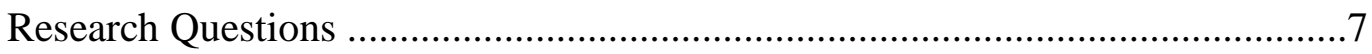

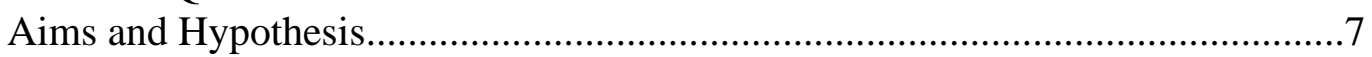

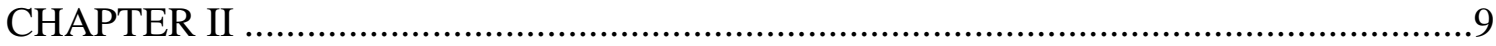

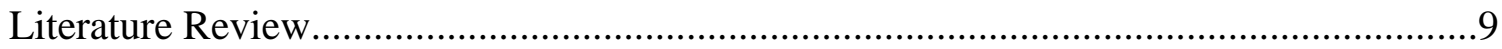

Video Game Use and Physical Health.............................................................

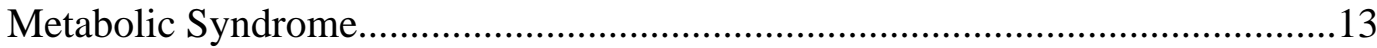

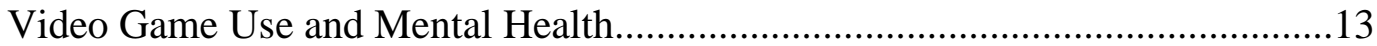

Video Game Use and Violence and Aggression.................................................15

Video Game Use and Problematic Mental and Social Health Outcomes...............19

Video Game Use and Mental and Social Health Benefits.....................................23

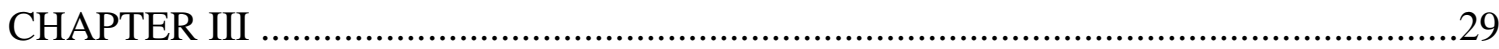

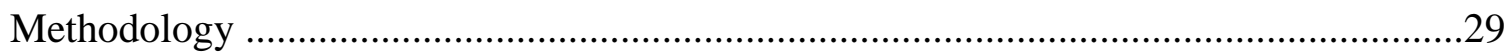

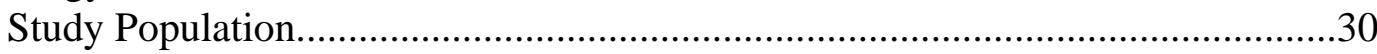

Statistical Analysis / Methods of Analysis...........................................................32

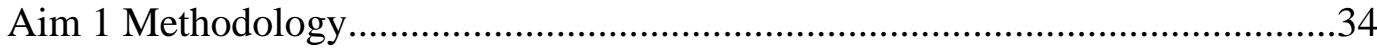

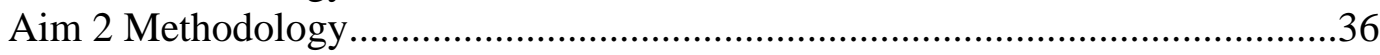

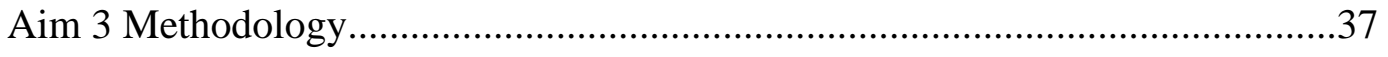

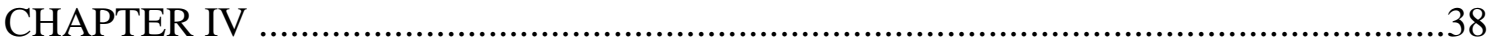

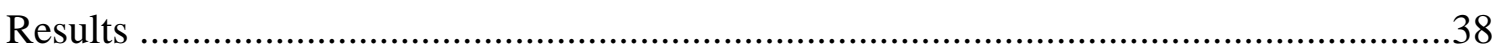

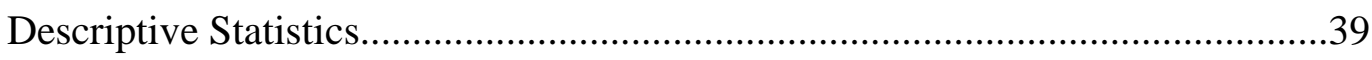

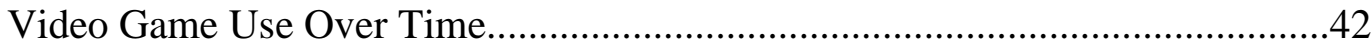

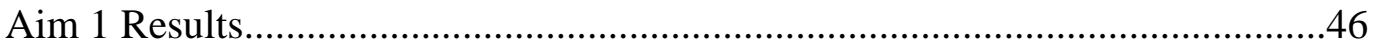

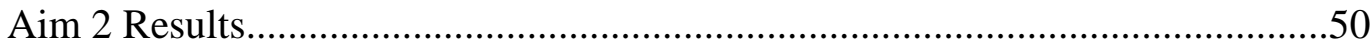

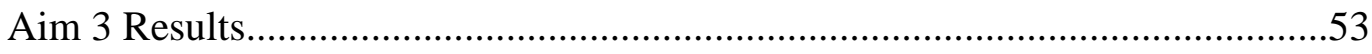

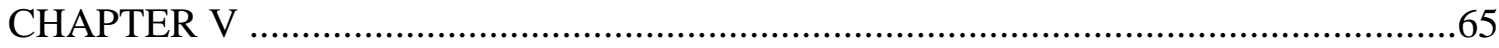

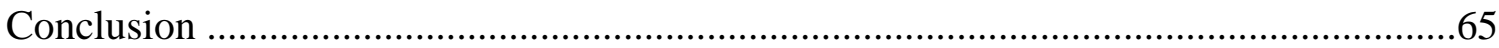

Effects of Life Course Theory Transitional Variables on Levels of Gaming ......65

Prevalence of Video Game Use and Gaming Disorder........................................67

Implications for Public Health Policy and Practice ……………………..............68

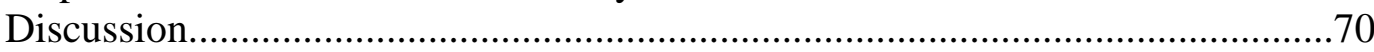


Recommendations...

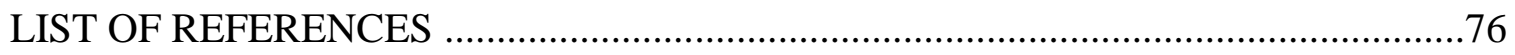

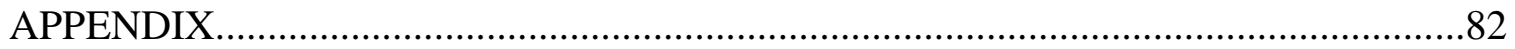

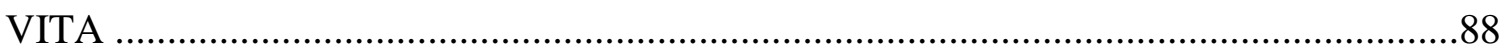




\section{LIST OF TABLES}

TABLE

PAGE

1. Add Health Study Population by Wave 30

2. Gender and Race / Ethnicity Demographic Characteristics for Add Health Wave IV

3. Weekly Gaming Hours Groups and Add Health Population Estimates at Wave IV.....41

4. Mean Hours of Gaming Separated by Add Health Wave Number. .43

5. Estimates of Fixed Effects Table for Weekly Hours of Gaming Over Time. ...

6. Mean Hours of Gaming for Gamers Only Separated by Add Health Wave Number...44

7. Estimates of Fixed Effects for Gamers Only..... .46

8. Metabolic Syndrome Risk Severity z-score, MetS z-score Components, and Demographic Characteristics for Add Health Wave IV....

9. Logistic Regression of Weekly Hours of Gaming at Wave IV Predicting Risk for Development of Metabolic Syndrome at Wave IV....

10. Logistic Regression of Weekly Hours of Gaming at Wave I Predicting Risk for Development of Metabolic Syndrome at Wave IV

11. Logistic Regression of Weekly Hours of Gaming at Wave IV Predicting Overall Violence and Aggression Scores at Wave IV

12. Logistic Regression of Weekly Hours of Gaming at Wave III Predicting Overall Violence and Aggression Scores at Wave IV....

13. Logistic Regression of Weekly Hours of Gaming at Wave I Predicting Overall Violence and Aggression Scores at Wave IV

14. Logistic Regression of Weekly Hours of Gaming at Wave III Predicting Sleep Problems at Wave IV 
15. Logistic Regression of Weekly Hours of Gaming at Wave IV Predicting Sleep Problems at Wave IV .54

16. Logistic Regression of Weekly Hours of Gaming at Wave III Predicting Depression Diagnoses at Wave IV 55

17. Logistic Regression of Weekly Hours of Gaming at Wave IV Predicting Depression Diagnoses at Wave IV

18. Logistic Regression of Weekly Hours of Gaming at Wave III Predicting ADD /ADHD Diagnoses at Wave IV

19. Logistic Regression of Weekly Hours of Gaming at Wave IV Predicting ADD /ADHD Diagnoses at Wave IV

20. Logistic Regression of Weekly Hours of Gaming at Wave III Predicting Having ever been Diagnosed with Anxiety / Panic Attacks Diagnoses at Wave IV

21. Logistic Regression of Weekly Hours of Gaming at Wave IV Predicting Having ever been Diagnosed with Anxiety / Panic Attacks Diagnoses at Wave IV

22. Logistic Regression of Weekly Hours of Gaming at Wave III Predicting Marijuana Use within the Last 12 Months at Wave IV 61

23. Logistic Regression of Weekly Hours of Gaming at Wave IV Predicting Marijuana Use within the Last 12 Months at Wave IV

24. Logistic Regression of Weekly Hours of Gaming at Wave III Predicting All Other Drug Use Except Marijuana within the Last 12 Months at Wave IV

25. Logistic Regression of Weekly Hours of Gaming at Wave IV Predicting All Other Drug Use Except Marijuana within the Last 12 Months at Wave IV .64 


\section{LIST OF FIGURES}

FIGURE

PAGE

1. Gender Distribution of the Add Health Sample.

38

2. Race and Ethnicity of the Add Health Sample

3. Weekly Gaming Hours Groups at Wave IV

4. Gaming Over Time Including Non-Gamers.

5. Mean Hours of Gaming for Gamers Only Separated by Add Health Wave Number...45

6. Overall Distribution of Met-S z-scores for Add Health at Wave IV 


\section{CHAPTER I}

\section{Introduction and Public Health Significance}

Adolescent engagement in video game use and its associations with both physical and mental health has been a controversial topic in the United States over the last several decades (Bean et al., 2017). A relatively new phenomenon, video game use in the United States among adolescents has grown from the emergence of the first widely available home video game console the "Atari 2600" in 1982 (Weesner, 2007) to an alarming 97\% of adolescents in the United States engaging in video game use on a weekly basis by the year 2008 (Lenhard et al., 2008). Video game use and health has been widely studied in Europe and Asia, however studies conducted in the United States have only managed to produce contradictory results (Ferguson and Colwell, 2017; Bean et al., 2017). Few studies to date have been conducted using longitudinal research designs and maintaining generalizability to the entire United States population (Gentile et al., 2011). As adolescents in the United States continue to play video games at increasingly alarming rates (Lenhard et al., 2008; Granic et al., 2014) public health researchers have consistently failed to reach a consensus about effects this increase in video game use is having on adolescents as they develop into adulthood (Ferguson and Colwell, 2017).

Sedentary behaviors that lead to extended periods of physical inactivity are associated with negative health outcomes such as increased risk for development of cardiovascular disease and diabetes (Panahi and Tremblay, 2018). However, in the United States, studies have consistently failed to separate hours of television viewing from engagement in video game use when studying adolescent health outcomes as they mature and transition into adulthood (Motl et al., 2006). The problem with previous 
studies failing to separate hours of television viewing from video game use is in the inherent differences between the two activities including but not limited to the amount of mental activity required from the user (Meyers, 2002). Playing a video game requires mental involvement from the user, often requiring attentiveness, problem solving skills, eye-hand coordination, communication and occasionally physical activity whereas television viewing requires almost no involvement from the viewer (Pomeroy, 2012).

Furthermore, studies in the United States have failed to reach conclusions in the ongoing debate about video games and psychological health outcomes in adolescents and adults (Ferguson and Colwell 2017, Bean et al 2017). Many studies have shown associations between video game use and problematic mental and social health outcomes including the tendency to develop violent behavior patterns (Gentile, 2009). Conversely, other studies have found associations between video game use and positive mental and social health outcomes in adolescents (Adachi and Willoughby, 2017). A vast majority of these contradictory studies have been conducted in small, non-generalizable samples with underpowered statistical analyses (Gentile et al., 2011). Using rigorous methodology guided by established theoretical framework, powerful statistical analysis, and the utilization of an existing data set that is truly representative of the United States population, this dissertation investigates associations between video game use and physical, social, and mental health outcomes of adolescents as they develop into adulthood. 


\section{Theoretical Framework}

\section{Life Course Theory}

Life Course Theory was naturally chosen as the guiding theoretical framework for this dissertation, both to guide the statistical analysis and inform / explain the resultant findings. Life Course Theory has been used as a guiding framework throughout varying behavioral sciences including sociology, psychology, and public health (George, 2015). Life Course Theory emphasizes the significant effects of major life experiences referred to as "transitions" on life trajectories over time and has been commonly utilized as a theoretical perspective to guide longitudinal studies of health-related outcomes (Evans et al., 2008).

Life Course theory finds its origins from research conducted throughout the 1960s and 1970s by prominent sociologists Elder, Cain, Riley, and Ryder. Research examining the stages of aging and how it affects day to day life led to the development of the theory. The earliest publication utilizing the Life Course Theory came in 1974, Elder used Life Course Theory with his research investigating the health outcomes of adults whose adolescence developed during the Great Depression that took place in the United States from 1929 to 1939 (Elder, 2018). Life Course Theory has been applied to a wide breadth of research investigating the developmental and social risks and protective factors that influence health outcomes over time (Stockwell et al., 2004). Transitions and turning points that influence the life course trajectories of individuals can be understood through the context of public health by focusing on how these transitions and turning points influence differing health behaviors and outcomes throughout various life stages explored through longitudinal study designs (Amstadter et al., 2009; Evans et al., 2008). The 
current dissertation utilizes the biographical paradigm of the Life Course Theory, as opposed to the institutional paradigm, in guiding the directional path of statistical analysis (George, 2015). The biographical paradigm is focused on patterns that relate to differing trajectories of an individual's life and the subsequently resultant outcomes over time. Framed within the biographical paradigm, this study examines adolescent transitions into adulthood and in doing so their societal changes in their statuses from dependent to independent as they experience major life transitions such as marriage, parenthood, and entrance to occupational careers (Berzin, 2010; Elder, 1998; Shanahan, 2000).

Life Course Theory is not only limited to explaining individual life outcomes, as it also can be utilized to investigate several outcomes related to shared collective experiences of groups or cohorts simultaneously (Dannefer, 2003). In addition, LCT can be used to help explain the observed effects of groups living through shared historic events, such as those living through the great depression (Elder, 2018).

Life course theory can provide invaluable insight into explaining the potentially significant role that major life experiences play on later health outcomes and help to inform the development of future health promotion interventions (George, 2015).

The data set from the National Longitudinal Study of Adolescent to Adult Health naturally lends itself to life course theory, as it has been successful in following adolescents' growth into young and early adulthood during which critical life course turning points are taking place. such as entry into parenthood, marriage, and entering and settling into occupational careers. This dissertation utilizes life course theory to 
investigate the effect that major critical transitions during early adulthood (ages 24-32)

have on the varying health outcomes related to long term engagement in video game use.

\section{Moral Panic Theory}

Despite many years of research, no scholarly consensus has been reached regarding the potential impact of engaging in video game use on adolescent aggression or a variety of other health outcomes such as the development of obesity and early onset of diabetes. A study conducted by Ferguson and Colwell in 2017 attempted to explain this lack of scholarly consensus by utilizing the moral panic theory framework. They found a continued lack of scholarly consensus on the topic of video game use, with only $15.3 \%$ of scholars endorsing the position that violent video game use contributes to measure of youth violence and aggression. As hypothesized by the researchers, older scholars tended to endorse more negative views of video game use. Scholars with preconceived negative attitudes toward adolescents themselves were also more negative in regard to engagement in video game use. They suggest that their findings that no scholarly consensus has been reached on the topic of video game use and youth violence has been the result of moral panic theory (Ferguson and Colwell, 2017). First popularized by Stanley Cohen in the early 1970's, Moral Panic Theory posits that with each new negatively culturally perceived event, group, condition, or episode that occurs in society, a moral panic will emerge at the group societal level (Cohen, 1972). Examples other than engagement in video game use of new additions to society which have caused moral panic is the war on drugs ("Drugs Report". Royal Society of Arts Action and Research Centre. March 2007. Retrieved 24 November 2014) and concerns over the effects of music lyrics (Deflem, 
2019). According to Cohen there exist five stages in the development of societal moral panic (Cohen, 1972; Cohen, 2011)

1. Someone, something, or a group is identified and defined as a possible threat to societal norms or communal interests

2. Threat is then depicted in a simple form by media

3. Portrayal of this form arouses public concern

4. Response from policy makers and authorities

5. Moral panic over the target issue results in societal changes that affect the community at large

\section{Social Determination Theory}

Social determination Theory may be a useful tool in explaining the positive effects of engaging in video game use. Research in the past that has focused only on the negative aspects of playing video games continues to support a problem oriented model of adolescent development and has neglected the important research question of how engagement in video game use can affect positive development for adolescents. Recent research has applied the Social Determination Theory to explain these positive effects of adolescent video game use.

The Social Determination Theory posits that engagement in video game use may satisfy three basic psychological needs: competence, autonomy, and social connectedness. It also may facilitate observed positive outcomes of video game use, such as increasing self-efficacy, functioning, learning, a sense of well-being, and development 
and maintenance of healthy positive relationships. Several studies have suggested that playing video games can satisfy these psychological needs (Ryan et al., 2006; Przybylski, 2009; Adachi and Willoughby, 2017).

This dissertation hypothesizes that the Social Determination Theory can provide an overarching theoretical framework for understanding the effects of playing video games on positive youth outcomes across a multitude of different public health domains.; while also investing tenets of Life Course Theory in examining possible associations between engagement in video game use and life transitions at a critical developmental stage, emerging adulthood.

\section{Research Questions}

What are the associations between video game use and physical, psychological, and social health outcomes over time?

\section{Aims and Hypothesis}

Aim 1 - Evaluate the cross-sectional association between self-reported weekly hours of video game use and the risk for development of metabolic syndrome

\section{Hypothesis 1 -}

$\mathbf{H}_{0}=$ There is no association between selected demographic characteristics and video game use across any waves of Add Health.

$\mathbf{H}_{1}=$ There is a statistically significant association between selected demographic characteristics and video game use across any waves of Add Health. 
Aim 2 - Evaluate the longitudinal association between self-reported weekly hours of video game use and measures of violence and aggression

\section{Hypothesis 2 -}

$\mathbf{H}_{0}=$ There is no association between weekly hours of video game use and selected measures of violence and aggression

$\mathbf{H}_{1}=$ There is a statistically significant association between weekly hours of video game use and selected measures of violence and aggression

Aim 3 - Evaluate the longitudinal association between self-reported weekly hours of video game use and various mental health outcomes

\section{Hypothesis 3 -}

$\mathbf{H}_{0}=$ There is no association between weekly hours of video game use and selected mental health outcomes

$\mathbf{H}_{1}=$ There is a statistically significant association between weekly hours of video game use and selected mental health outcomes 


\section{CHAPTER II}

\section{Literature Review}

\section{Video Game Use and Physical Health}

Two landmark studies conducted in 2004 came to the early conclusion that there exists a negative association between video game use and an active lifestyle that leads to attaining recommended levels of physical activity in the United States.

The first of such studies was a meta-analysis authored by Marshall et al. in October of 2004 out of San Diego State University. They highlighted a statistically significant negative association between engaging in video game use and physical activity attainment in children and youth and found relationships between media use, body fat content, and physical activity attainment in youth. They noted, however, that although the association they found was statistically significant, it was small in magnitude and possibly not of clinical relevance. Therefore, the study lacked external validity and generalizability to the United States population (Marshall et al., 2004).

The other study published in 2004, authored by the same group of researchers out of San Diego State University, found that most children and adolescents tend to not exceed recommended daily hours of television viewing and that physical activity is unrelated to television viewing. This finding suggests that youth can concurrently be sufficiently active and exceed screen-time recommendations (Biddle et al., 2004). However, just two years later, a study conducted by a team of researchers out of the University of Illinois found opposing results to Biddle's findings. Using latent growth curve analysis modeling, researchers were able to show decreases in time spent viewing 
television (and engaging in video game use) were associated with an increased frequency in reported leisure time physical activity attainment by children and adolescents. These findings suggest that youth and adolescents obtain more physical activity as screen time decreases (Motl et al., 2006).

Research on the topic remained inconsistent and inconclusive for several years until a study was published in 2011 by Goldfield et al., which demonstrated that video game use was independently associated with both blood pressure and lipids in obese and overweight children and adolescents. Researchers found that seated video game use was the only sedentary behavior associated with elevated blood pressure and lipids before and after adjustment for age, sex, pubertal stage, parental education, caloric intake, body mass index, percent intake of dietary fat, and physical activity duration and intensity. Specifically, they showed that video game use remained positively associated with systolic blood pressure (adjusted $\mathrm{r}=0.13, \mathrm{~b}=1.1, \mathrm{p}, 0.05$ ) and total cholesterol / HDL ratio (adjusted $\mathrm{r}=0.12, \mathrm{~b}=0.14, \mathrm{p}, 0.05$ ). Their findings provided support for reducing time spent playing seated video games as a possible means of health promotion and to prevent the incidence of cardiovascular disease risk factors in overweight and obese youth and adolescents. They urged that future research should attempt to replicate their findings using longitudinal research methods and subsequently aim to uncover the mechanisms which link engagement in video game use and both elevated lipids and blood pressure measurements in this population of adolescents who are at high risk to develop cardiovascular disease. (Goldfield et al., 2011). However, contradictory results were soon to follow, just one year after Goldfield's findings were published, a new study conducted by researchers from the Cambridge University school of public health and 
published in the Journal of the American Medical Association found opposing results showing that higher frequency of physical activity time by children and adolescents was associated with better cardiovascular and metabolic syndrome risk factors regardless of the amount of sedentary time attained, suggesting that leisure time sedentary activities may have no association with cardiovascular disease risk factors (Ekelund et al., 2012).

Another major metabolic syndrome risk factor, obesity has also been shown to be associated with frequent video game use in adolescents. In 2012 a nationally representative study of Canada, conducted by Casiano et al., found that obesity was associated with frequent television and video game use (Adjusted Odds Ratio (AOR) 1.10). Every health outcome except for obesity that was tested for including things such as depression, risky sexual behaviors, and binge drinking were shown to be less likely in adolescents and youth who reported frequent video game and or computer use (AOR 0.92). This shows that while video game use may potentially have a protective component against psychological factors and risky social behaviors, the effect of frequent video game use on obesity could pose to be a devastating public health dilemma to a population already suffering from an obesity epidemic (Casiano et al., 2012).

Another contradictory study published in 2012 out of Spain by Devis-Devis et al., which contradicts the previously discussed findings by Marshall et al. (2004) and Motl et al. (2006), reported negative associations between video game use and physical activity obtainment in adolescents, and found positive associations between time spent engaged in computer and video game use and light physical activity attainment on weekends in children and adolescents. These findings suggest a lack of displacement of participation 
in physical activity by time spent playing video games or using the computer in adolescents and youth (Devis-Devis et al., 2012). While these findings seemed promising in suggesting that video game use may not be a major threat to long term health outcomes, they have been increasingly met with opposition, as research on the topic continued to accumulate. Limitations of this study included a low sample size $(n=323)$ and low external generalizability outside of Spain.

In 2014 a study conducted by researchers at the University of Newcastle in Australia examined the relationship between video game genres and physical activity attainment from a sample of adolescent boys from low income communities in South Wales, Australia. Findings suggested that game genre may affect physical activity and screen time. They also investigated the proposed hypothesis of a displacement effect, which postulates that time spent in sedentary behaviors displaces time that could be spent engaging in health-enhancing physical activity. Their findings supported the evidence of a displacement effect, suggesting that game genre influences physical health outcomes. Strategy and role playing games were shown to be associated with obtaining less physical activity; while sports and racing games were shown to be associated with an increase in physical activity attainment (Thorne et al., 2014). These findings seem to directly contradict the previously discussed findings of Devis-Devis et al. who found a lack of displacement of participation in leisure time physical activity by time spent playing video games (Devis-Devis et al., 2012).

These contradictory findings in the literature provide a great need for this present research to investigate the association between video game use and physical activity, 
obesity, and risk for the development of cardiovascular and metabolic issues in adolescents and adults in the United States. A multitude of these studies were conducted using national data sets and longitudinal research designs, however, most lacked external generalizability to the United States population and those conducted within the United States only managed to produce contradictory results.

\section{Metabolic Syndrome}

Video game use has been shown to contribute to increased BMI in both adolescents and adults. As such, this dissertation investigates if engagement in long term video game use is associated with the development of metabolic syndrome over time. Metabolic syndrome is a group of associated risk factors including high waist circumference, high blood pressure, high fasting blood glucose, and high cholesterol levels. It is well documented that risk for cardiovascular mortality is increased in persons found to have metabolic syndrome (Isomaa et al. 2001). In 2006 a study published from the Department of Endocrinology and Metabolic Medicine at St Mary's Hospital in London, United Kingdom concluded that metabolic syndrome is not only a public health problem in the United States but is also fast becoming a global public health concern (Alberti et al. 2006). Metabolic Syndrome has been found to affect approximately 25\% of the global population, and nearly 35\% of the United States population (Mozaffarian et al., 2008). Currently, we are unaware of any existing research findings on the association between video game use and the development for the risk of metabolic syndrome.

\section{Video Game Use and Mental Health}

The earliest research into the topic of video game use and health started with the widespread idea that violent video game use caused aggression in children and 
adolescents. The earliest studies seemed to show conclusive evidence that there was a strong positive association between the use of violent video games and aggressive tendencies and a negative association between the use of video games and prosocial behavior (Lenhart et al., 2008; Birkland and Lawrence, 2009; Willoughby, Adachi, and Good, 2012; Kovess-Masfety et al., 2016; Adachi and Willoughby 2017; Trisolini et al, 2018). This idea was further exacerbated by the tragic Columbine school shooting that took place on April 20 ${ }^{\text {th, }}$ 1999. Two male high school seniors killed a teacher and twelve students, in what marked the deadliest school shooting in United States history at the time and sparked a series of copycat school shootings including the 2001 Red Lake Massacre, the Virginia Tech shootings, and many others (Chyi and McCombs, 2004). The two perpetrators of the Columbine massacre were known to frequently play a violent and graphic video game called "Doom" in which the player controls an avatar in first person view and shoots computer generated character models. The pair even went so far as to create their own version of the game in which they dressed their avatars in trench coats and killed student athletes (Radford, 2000).

This led to a state of moral panic in the United States (Ferguson and Colwell, 2017) and thus, for over a decade the consensus among both the scientific community and the general population was there exists a clear link between violent video game use and the development of aggression in adolescents (Birkland and Lawrence, 2009). However, new studies have since shown contradictory results, with a breadth of new research suggesting that video game use, regardless of game genre, may have positive social and psychological effects on youth and adolescents as they develop into adulthood (Lenhart et al., 2008; Willoughby, Adachi, and Good, 2012; Kovess-Masfety et al., 2016; 
Adachi and Willoughby 2017; Trisolini et al, 2018). This topic is still currently under much debate and scrutiny, with advocates on both sides of the coin pushing their agendas (Ferguson, 2015; Bean et al., 2017). Therefore, a main objective of this dissertation is to examine the effects of video game use over time on psychological and social health outcomes in youth and adolescents as they develop into adults in the United States.

\section{Video Game Use and Violence and Aggression}

In 2001, the first major landmark meta-analysis study investigating the effects of violent video game use on aggressive behavior, aggressive cognition, aggressive affect, physiological arousal, and prosocial behaviors in developing adolescents was published by researchers Anderson and Bushman from Iowa State University. Their research revealed an alarming finding, demonstrating violent video game use increases aggressive behavior in children and adolescents. Confirming long held beliefs, exacerbated by several school shootings, that violent video games caused aggression in youth. They also found that exposure to violent video games may increase physiological arousal and thoughts and feelings related to aggression in adolescents. In addition, they found that playing violent video games also decreased prosocial behavior (Anderson and Bushman, 2001). Reports on their finding in conjunction with biased reporting from media and news outlets led to an early widespread moral panic throughout both the general United States population and the scientific community and the acceptance of the idea that violent video games cause aggression (Ferguson and Colwell, 2017).

In 2004, a prominent researcher on the topic of video game use and aggression in youth, Douglas Gentile from Iowa State University, attempted to explain the previously observed aggression in youth who engage in violent video game use. He authored a paper 
in partnership with researchers from the University of Oklahoma Medical School which confirmed the previous findings from Anderson and Bushman, as well as showed evidence that adolescents and youth who expose themselves to greater amounts of violent video game use were found to be more hostile, reported getting into more arguments with both teachers and care takers, were more likely to be involved in physical violence, and performed more poorly in school as compared to their non-violent video game playing counterparts. They supported and interpreted their results using the General Aggression Model, which has remained the basic framework for interpreting aggressive outcomes in youth who engage in violent video game use (Gentile et al., 2004).

The idea of violent video game use causing aggression in youth remained accepted and unchallenged for the better part of a decade. Only in 2011, new research began to challenge findings that engaging in violent video game use may actually decrease violence and risk behaviors in both children and adolescents.

This new alternative view was led by a breakthrough study in 2011 by Adachi and Willoughby which called for the need for a greater understanding of the effects of violent video games on youth and adolescent aggression. Researchers argued that not until the characteristics of individual games are held to a constant and unambiguous measure of aggression that the influence of violent content in video games on aggression in youth and adolescents can be assessed (Adachi and Willoughby, 2011). A subsequent study by Adachi and Willoughby was published in 2012 in which they examined the effect of video game competition and violence on aggressive behavior and found that video game use among their sample promoted positive youth development (Adachi and Willoughby, 2012). A recent study by Willoughby, Adachi, and Good, investigated the long term 
relationship between engaging in violent video game use and aggression among adolescents utilizing a longitudinal study design examining specific game characteristics. They found that sustained violent video game use was significantly related to sharper increases in adolescents' trajectory of aggressive behavior over time. Furthermore, they found that greater amounts of violent video game play predicted higher levels of aggression over time, after controlling for previous levels of aggression. Non-violent video game play also failed to predict higher levels of aggressive behavior over time in youth and adolescents as they develop into adulthood. These findings, and the fact that many adolescents play video games for more than several hours every day, highlights the need to achieve a greater understanding of the long term relationship between violent video games and aggression in youth, as well as the specific game characteristics (e.g., violent content, competition, pace of action) that may be responsible for this association (Willoughby, Adachi, and Good, 2012). This study was crucial in understanding the varying effects of game genre on aggressive outcomes, suggesting that only certain game types are associated with aggressive behavior in adolescents and youth.

In the same year another group of researchers, Cunningham, Engelstatter and Ward, were investigating the relationship between violent video game use and the perpetration of violent crimes. They argued that all previous studies on the topic had lacked external validity and could not account for either aggressive effects of alternative activities video game playing substitutes for or for the possible selection of relatively violent persons into engaging in violent video game use. Their results were consistent with two opposing effects. Firstly, they supported the behavioral effects as in the psychological studies. Secondly, they suggested a larger voluntary incapacitation effect in 
which playing either violent or non-violent games decreases crime perpetration. They found that overall, violent video game use led to decreases in violent crimes. They modified the Becker and Murphy (1988) addition model to a video game setting to get a version of the General Aggression Model to explain their findings. They observed that new releases of popular video games often resulted in long hours of play by gamers. They then applied the time allocation model of Becker (1965) to a video game setting to show a term "voluntary incapacitation" to explain the reduction in violent crime outcomes (Cunningham, Engelstatter, and Ward, April 2011).

A study conducted in 2017 by researchers Decamp and Ferguson from Western Michigan University found small correlations between youth engagement in violent video game use and violence-related outcomes which they suggested may be due to other factors, including a wide range of possible effects from covariates such as gender, mental health, and varying social influences. Furthermore, they showed that models examining video game use and violence related outcomes without controls tended to return small, but statistically significant relationships between violent game use and violence related outcomes. However, once other predictors were included within the models and once propensity scores were used to control for an underlying propensity for choosing or being allowed to play violent video games, those relationships vanished, became inverse, or were reduced to trivial effect sizes (Decamp and Ferguson 2017). Their results offer further support to the conclusion that video game violence is not a meaningful predictor of youth violence and, instead, support the conclusion that both family and social variables act as more influential factors. 
Despite decades of study, no unifying scholarly consensus has emerged regarding violent video games contribution to youth and adolescent violence or other concerns related to public health (Ferguson and Colwell 2017, DeCamp and Ferguson 2017).

\section{Video Game Use and Problematic Mental and Social Health Outcomes}

Several studies have highlighted potential negative mental and social health outcomes over time for adolescents who engage in extended hours of video game.

One of the first of such studies was conducted by Gentile et al. in 2009. While a few studies had been conducted on the topic beforehand, previous research had been biased by the use of convenience samples that never reached beyond local geographical regions. This study by Gentile and colleagues used a national sample of youth in the United States. Gentile gathered information about youth habits and involvement of parents in video game use. The main goal was to identify the percentage of youth in the United States who could potentially meet the clinical criteria for pathological gaming. Although the current DSM-5 criteria for internet gaming disorder was not yet available in 2009, Gentile and colleagues used similar parameters in what he estimated would be a clinical style diagnosis for pathological gaming. The study utilized a Harris poll, (from Harris Insights and Analytics, one of the longest running surveys measuring public opinion in the United States) which surveyed a sample selected at random of 1,178 youth from the United States ages eight to eighteen. Their findings indicated that approximately $8 \%$ of youth engaged in video game use in this sample demonstrated pathological signs and patterns of play consistent with the criteria. Several indicators that were used had documented both rigorous convergent and divergent validity of the results. They found 
that those identified as pathological video game users were spending twice as much time playing as non-pathological gamers and furthermore, pathological gamers were shown to be receiving lower grades in academics; pathological video game use also showed a comorbidity with several attention problems. The final contribution was the finding that pathological status significantly predicted poorer school performance even after controlling for sex, age, and weekly amount of engagement in video game use (Gentile et al., 2009) These results confirmed that pathological gaming can be measured reliably, that the construct used demonstrated validity, and that it is not simply isomorphic with high amounts of video game use.

The findings in the previous study led Gentile and colleagues to investigate further into the phenomenon of video game use among youth and the development of what is considered pathological gaming. Another more rigorous study was conducted by Gentile et al. and the results were published in 2011 in a paper entitled "Pathological Video Game Use Among Youths: A Two-Year Longitudinal Study". In this study they found that the prevalence of pathological gaming among youth was not different from what was found in several other countries. Increased amounts of gaming were associated with, having a lower social competence, and a greater tendency for impulsivity were found to be acting as risk factors for becoming pathological gamers. They also found that the presence of depression, increased anxiety, abnormal social phobias, and poorer performance in school seemed to be outcomes of pathological gaming rather than risk factors. This study adds important information to the discussion about whether video game "addiction" is like other similar addictive behaviors, demonstrating that the effects of prolonged video game use can potentially last for many years and it is not solely a 
symptom of co-morbid disorders. Almost all the studies that have been conducted to date have relied on measurements at a single time point or on case studies. This study stands out for its longitudinal design. Unfortunately, due to the limitation of a small sample size and the relatively short two-year time frame, most of the questions about the associations between video game use in youth and the development of pathological gaming behaviors were not answered by this study and require further investigation. Furthermore, because these outlier conditions and behaviors affect only small proportions of the population, much larger samples sizes are needed to tease out the true association between video game use over time and the development of game use behaviors consistent with the then currently validated definition of pathological gaming. The researchers identified that future studies with larger sample sizes and longitudinal study designs that are representative of the United States population were needed (Gentile et al., 2011). These findings provide further evidence that the longitudinal study design of the National Longitudinal Study of Adolescent to Adult Health (Add Health) is ideal for answering the research questions put forth by this dissertation.

In 2013 the term Internet Gaming Disorder was included as a diagnosis in section III of the Diagnostic and Statistical Manual of Mental Disorders 5 (Petry and Obrien, 2013). The American Psychiatric Association had categorized proposed criteria for the condition of Internet Gaming Disorder; however, the disorder was not yet codified. By placing Internet Gaming Disorder in section III of the DSM-5 the American Psychiatric Association acknowledged Internet Gaming Disorder as an impulse control disorder, however further research was necessary before Internet Gaming Disorder was to be categorized as an indicatable disorder within the main section of the DSM-5. Proposed 
criteria for this condition include: Preoccupation with internet games; Withdrawal symptoms when internet gaming is taken away; Tolerance with internet game play; Unsuccessful attempts to reduce or control internet gaming; Loss of interest in other hobbies or entertainment; Continued excessive use despite psychosocial problems ;Underreports or deceives others regarding their internet gaming use; Uses internet games as a form of escapism from negative affective states or emotions; Has jeopardized social relationships, occupations, or their education because of internet gaming (American Psychological Association DSM-5, 2013). The criteria for Internet Gaming Disorder also includes the criteria that the individual must be engaging in more than six hours per day of non-academic and non work-based internet usage. The only major limitation of the American Psychiatric Association criterion for Internet Gaming Disorder is that the definition is limited to internet gaming and does not include general use of the internet. This affirmed and validated definition for internet gaming disorder gave rise to a new wave of studies investigating the mechanisms of internet gaming disorder. Several studies were conducted on the features of relationships between adolescents and parents in youth who fit the criteria for Internet Gaming Disorder (Kuss et al., 2017).

In 2016 a study conducted by King and Delfabbro investigated the features of Parent-Child Relationships in Adolescents with Internet Gaming Disorder and investigated the effects on parameters such as alienation, communication, and trust in the context of youth who fit the criteria for Internet Gaming Disorder. Investigators used a survey disseminated to school aged adolescents aged $12-17(\mathrm{n}=824)$ including questions about their internet gaming use and questions designed to emulate the internet Gaming Disorder checklist. Their results showed that youth who displayed the behaviors 
of internet gaming disorder had reported statistically significant lower amount of trust and communication with parents. Additionally, youth with high risk for development of Internet Gaming Disorder showed a statistically significantly increased time engaged in video game use online with strangers. They also found that youth who played Massive Multiplayer Online games were more likely to develop behaviors associated with Internet Gaming Disorder. Although this study showed that family conflict can potentially be one of the negative results of youth engaging in problematic gaming, their results suggested that issues with parent child relationships may only have a weak correlation to internet gaming problems overall (King and Delfabbro, 2016). The results of this study further validate the need for the current dissertation which will be able to either support or refute the resultant claims brought forward by the researchers as to the effect of problematic gaming in adolescents and the effect on parent child relationships.

\section{Video Game Use and Mental and Social Health Benefits}

While the negative effects of using video games over time may seem obvious, there are many positive effects / benefits to long term mental and social health outcomes for adolescents who engage in video game use which have been identified in the literature in recent years, contradicting the findings of previous studies that have concluded that engaging in video game use is harmful to adolescents.

Until 2008, it was widely believed that video game use was detrimental to healthy adolescent mental and social development (Gentile and Gentile, 2008). However, a pair of studies published in 2008 gave insights into possible positive effects of adolescent video game use and sparked the debate on whether the benefits of playing 
extended hours of video games outweigh the associated risk factors. A study conducted by the PEW research center led by Amanda Lenhart investigated teens' gaming experiences in the United States. The survey provided the first look into a nationally representative study of teen video game play and of teen video game use in the United States. The survey looked at which teens were engaging in video game use, the specific games which they played, the equipment they were using, the varying social context of their online environments, and the role which parents and parental monitoring of video game use plays on teen outcomes. Results indicated 97\% of teens in the United States aged twelve to seventeen self-reported playing either computer, portable, console, or web browser-based games. One of the major findings from this study was the identification that video game use was often a social experience for adolescents and teens. Researchers found that youth in the United States play games in a multitude of ways, including with other teens in person, with other players via the internet, as well as by themselves. Additionally, they found that while most teens engage in video game use by themselves at least on occasion, only $24 \%$ of teens who reported playing video games only play games by themselves, and the remaining $76 \%$ of teens, reported playing games with others. Researchers identified both anti-social and pro-social behaviors among teens who play video games. They also found that the quantity of video game use was not related to a majority of civic outcomes, but rather some individual qualities of video games themselves seem to have a strong positive relationship to a host of civic outcomes. Researchers found very little evidence to support the claim that engaging in video game use promotes attitudes or behaviors which would potentially undermine civic behavior. (Lenhart et al., 2008) Overall, this research helped to pioneer the idea that video game 
use among adolescents in the United States may have positive social outcomes, as well as identified the first suggested prevalence rates for video game use among youth in the United States.

Another study published in 2008 by Willoughby entitled "A Short-Term Longitudinal Study of Internet and Computer Game Use by Adolescent Boys and Girls: Prevalence, Frequency of Use, and Psychosocial Predictors" supported the findings from the PEW research study, replicated in a Canadian sample. While this study was not conducted in the United States, the social and geographic similarity between the United States and Canada makes this paper highly relevant the topic of video game use among adolescents in the United States. Frequency, prevalence and mental and social predictors of video game and computer use were analyzed with 788 female and 803 male adolescents enrolled in grades 9 and 10, across two separate time periods, two years apart. This study found that being of male gender acted as a significant predictor of both engaging in computer game and internet use. Trends in favor of increased positive friendship quality and decreased positive parental relationships predicting higher frequency of Internet use were identified, suggesting that adolescents who engage in video game use are more likely to have positive social relationships among peers but less likely to have positive parental relationships. Lastly, moderate use of the internet was found to be associated with higher levels of academic achievement than adolescents with no internet or high internet gaming use. These findings further supported the idea that engaging video game use may have positive social outcomes for adolescents (Willoughby, 2008) 
Willoughby followed up the 2008 study with another study published in 2012 investigating the association between video game use and the promotion of positive youth development. Researchers found that engaging in video game use meets Larson's criteria for promoting positive youth development (Willoughby et al., 2012). Their findings suggest that video games promote positive youth development, adding further support to the concept that video game use may have positive social outcomes for adolescents as they develop into adulthood.

In 2014 researchers Drummond and Sauer conducted a study published in PLOS ONE which analyzed data from over 192,000 adolescents across 22 countries in an attempt to estimate the true effect of frequency of video game use on academic achievement in mathematics, reading, and sciences. Contrary to popular claims at the time that engaging in high amounts of video game use will result in worsened performance academically, differences found in academic performance were negligible regardless of the frequency of video game use. Researchers concluded that engagement in video game use did not have a statistically significant impact on adolescent's academic achievement scores and did not negatively impact academic performance in science, mathematics, or language arts (Drummond and Sauer, 2014).

Over time, more research began to emerge on the positive effects of video game use in adolescents, including a study published in 2014, suggesting surgeons who have some experience playing video games performed laparoscopic surgery faster and made fewer mistakes (Rosser et al., 2014). A study published in 2016 by researchers from Columbia University found that in Western Europe, approximately $20 \%$ of children played video games at least 5 hours per week. Further Investigations of the mental health, 
cognitive abilities, and social skills of youth in Western Europe found that high amounts of video game use were associated with 1.75 times the odds of having high intellectual functioning, and 1.88 times the odds of high overall competence in school. When they controlled for high usage predictors, they found no significant association with any adolescent self-reported or parent / teacher reported mental health issues. They also found that high video game use was associated with a decrease in relationship problems with peers. They concluded that engaging in video game use may have a potentially positive effect on children and adolescents as they develop into adults (Kovess-Masfety et al., 2016). However, this study was limited in external validity and may not be generalizable to the United States population.

By 2015 there existed enough literature to conduct meaningful meta analyses on the topic of video game use and adolescent development into adulthood. In 2015, prominent researcher Christopher Ferguson conducted a meta-analysis which looked at 101 studies on video game use and associations with multiple parameters of adolescent development. Study findings suggested that video game had minimal influences on reduced academic performance $(\mathrm{r}=-.01)$, reduced prosocial behavior $(\mathrm{r}=.04)$, increased aggression $(r=.06)$, attention behavior symptoms $(r=.03)$, and depression $(r=.04)$. The analysis notes that issues related to researchers bias also continue to be common problems for the most video game use research. Ferguson claimed that publication bias is a major problem for studies conducted on the association between video game use and outcomes of youth violence and aggression. Future recommendations included that subsequent research should address video game use from a public health perspective (Ferguson, 2015). 
In 2017, researchers Adachi and Willoughby sought to explain the positive effects that were being found among adolescents who engage in video game use. In a paper titled "The Link Between Playing Video Games and Positive Youth Outcomes" they investigated the possible role that the Social Determination Theory could play in explaining the positive effects associated with video game use. They found that the Social Determination Theory provided a framework to explain the positive effects of playing video games on youth across several domains such as physical activity, well-being, and intrinsic motivation. They concluded that future research should focus on testing their hypotheses by assessing whether satisfying varying psychological needs while playing video games can possibly act as a mediator for the positive associations identified. They suggest future research to investigate the mechanism of how certain video games can positively affect youth development over time by incorporating longitudinal study designs (Adachi and Willoughby, 2017). 


\section{CHAPTER III}

\section{Methodology}

\section{Study Population}

\section{The National Longitudinal Study of Adolescent to Adult Health (Add Health)}

The study population comes from the National Longitudinal Study of Adolescent to Adult Health, referred to as Add Health. Add Health is a school-based longitudinal study of a nationally representative sample of adolescents in grades 7-12 in the United States in 1994-95. Add Health was initiated in 1994 and is supported by three program project grants from the Eunice Kennedy Shriver National Institute of Child Health and Human Development including funding from over 23 other United States governmental foundations and agencies (P01-HD31921).

Data have been collected from adolescents, their fellow students, school administrators, parents, siblings, friends, and romantic partners through multiple data collection components, including four respondent in-home interviews. Study population by wave is shown in appendices figure 1.

In addition, existing databases with information about respondents' neighborhoods and communities have been merged with Add Health data, including variables on income and poverty, unemployment, availability and utilization of health services, crime, church membership, and social programs and policies (Harris, 2013). For the purposes of this proposed dissertation, data will be analyzed from Add Health Waves I, II, III, and IV. Data from Wave V have not yet been made available. Study population respondent values and biomarker collection data is shown in table 1. 
Table 1. Add Health Study Population by Wave

\begin{tabular}{|c|c|c|c|}
\hline & $\begin{array}{l}\text { In-School } \\
\text { Administration }\end{array}$ & $\begin{array}{l}\text { In-Home } \\
\text { Administration }\end{array}$ & $\begin{array}{l}\text { Biomarker } \\
\text { Collection }\end{array}$ \\
\hline $\begin{array}{l}\text { Wave I } \\
\text { 1994-1995 } \\
(79 \%) \text { [retention } \\
\text { rate] }\end{array}$ & $\begin{array}{l}\text { Students } \\
\mathrm{n}=90,118\end{array}$ & $\begin{array}{l}\text { Adolescents in } \\
\text { grades } 7-12 \\
\mathrm{n}=20,745\end{array}$ & Height, weight \\
\hline $\begin{array}{l}\text { Wave II } \\
1996 \\
(88.6 \%)\end{array}$ & & $\begin{array}{l}\text { Adolescents in } \\
\text { grades } 8-12 \\
\mathrm{n}=14,738\end{array}$ & Height, weight \\
\hline $\begin{array}{l}\text { Wave III } \\
2001-02 \\
(77.4 \%)\end{array}$ & & $\begin{array}{l}\text { Young Adults Aged } \\
18-26 \\
n=15,197\end{array}$ & $\begin{array}{l}\text { Height, weight, } \\
\text { STI, HIV, genetic }\end{array}$ \\
\hline $\begin{array}{l}\text { Wave IV } \\
2008 \\
(80.3 \%)\end{array}$ & & $\begin{array}{l}\text { Adults Aged 24-32 } \\
\mathrm{n}=15,701\end{array}$ & $\begin{array}{l}\text { Height, weight, } \\
\text { waist, metabolic, } \\
\text { immune, } \\
\text { inflammation, } \\
\text { cardiovascular, } \\
\text { medications, } \\
\text { candidate genes, } \\
\text { genome-wide } \\
\text { association }\end{array}$ \\
\hline $\begin{array}{l}\text { Wave V } \\
2016-18 \\
\text { (not currently } \\
\text { available) }\end{array}$ & & $\begin{array}{l}\text { Adults Aged 32-42 } \\
\text { Target: } 19,828\end{array}$ & $\begin{array}{l}\text { Height, weight, } \\
\text { waist, metabolic, } \\
\text { immune, } \\
\text { inflammation, } \\
\text { cardiovascular, } \\
\text { medication, renal, } \\
\text { gene expression }\end{array}$ \\
\hline
\end{tabular}

Add Health followed a sample of adolescent students in the United States in grades 7-12 during the 1994-1995 school year. Add Health is a program project directed by researchers at the Carolina Population Center, located at the University of North Carolina at Chapel Hill (Kelley and Peterson, 1997). Add Health was mandated by the United States Congress for the purpose of measuring the role the social environment 
plays on adolescent health issues and to study adolescents in the United States on a national scale as they mature into adulthood (Harris, 2013). The sample selected resulted from an extensive effort to obtain a nationally representative sample of adolescents as they develop into adults in the United States. A wide range of health behaviors were examined which directly affect health outcomes related to both the study participants general health as well as a variety of future health outcomes as they continue to age into early adulthood and beyond. Researchers from Add Health also sought to make the dataset accessible to public health, medical, and other professionals, allowing a comprehensive range of professionals to benefit from the findings of the study. The cohort was subsequently followed throughout the years and interviewed within their homes at four additional time points. Data have been collected from adolescents, their fellow students, school administrators, parents, siblings, friends, and romantic partners through multiple data collection components, including four waves of in home interviews (Harris, 2013). Study population by wave is shown in Appendix Table 1. The present study analyzes data through the first four waves of Add Health. Wave I was collected in 1994-1995 when participants were enrolled in grades 7-12, Wave II in 1996 when participants were enrolled in grades 8-12, Wave III was collected in 2001-2002 when participants were aged 18-26, and Wave IV was collected in 2008 when the participants were 24 to 32 years old and settling into young adulthood. Through Wave IV data collection, the researchers obtained longitudinal survey data on the social, economic, psychological, and health circumstances of the respondents, as well as longitudinal geographic data. Several features of the Wave IV data collection represented new directions for Add Health, including methods to obtain more objective measures of health 
status and health behavior to capture prevailing health concerns, and methods to obtain biological markers of future chronic health conditions and disease. Wave IV employed innovations in the collection of biological measures in a field setting on a large national sample that were both practical and groundbreaking. This allowed for the present study to analyze physical data that was not previously available. (https://www.cpc.unc.edu/projects/addhealth/design/wave4).

Public-use data files were downloaded from the University of North Carolina Dataverse website at web address; https://dataverse.unc.edu/dataverse/addhealth, the SAS data files were then converted into SPSS files. All relevant data sets were merged, using Wave IV data files, including the in-home questionnaire (w4inhome_fmt_data), Lipids (w4lipid), Glucose (w4glucose), and the appropriate weight files (w4weight). The data was then cleaned with all outliers and missing responses being identified and removed. Appropriate complex samples analysis plan was created to account for cluster and weight of the Add Health data set to estimate findings to the United States population at large (Harris et al., 2006).

\section{Statistical Analysis / Methods of Analysis}

Statistical analysis was performed using SPSS version 25 data analysis and statistical software, accessed online through Florida International University eLabs application software. The Add Health study design used a clustered study design in which the clusters were sampled with unequal probabilities. While this functioned to decrease the overall costs of data collection, this specific design measure complicated subsequent statistical analysis because the observations no longer remained 
independently and identically distributed. To correctly analyze the data collected from Add Health requires the use of specially allocated survey software packages designed to handle observations that aren't distributed independently and identically. Previous versions of SPSS were unable to handle such analysis, however the current SPSS version 25 is updated to run design observations that are not distributed independently or identically. In addition, the public use data sets of Add Health made available have been properly weighted to account for the cluster sampling with unequal probabilities.

Multiple logistic regression analysis modeling was conducted to test the association between reported weekly hours of video game use across all waves of Add Health on physical, mental, and social health outcomes in Wave IV. Binomial Logistic Regression and Ordinal Logistic Regression modeling was conducted to test the association of each Wave I, III, and IV independent variables adjusted for other independent variables in order to predict Wave IV outcome variables.

Since no biomarker data was collected in the early waves (Waves I, II, and III) research question 1 investigating the association between weekly hours of video game use and the development of metabolic syndrome utilized a cross-sectional study design approach to investigate possible statistically significant associations. While this limitation weakens the statistical analysis for the first aim, the overall strength of the Add Health study design allows the current study to still contribute valid results which could have an impact on future public health research on the topic of video games and health in the United States. 
To test for the influence of major life turning points as guided by the Life Course Theory framework, demographic variables from the Add Health data set on marriage, and education were controlled for in each independent analysis, as well as Gender and Race / Ethnicity.

To ensure that results were not due to chance, alpha level for each independent analysis was set at 0.05 , or a $95 \%$ likelihood that the results found will not be due to chance if statistical significance is reached. Results returning p-values between .05 and .1 were considered marginally significant.

Variable categories were created, separated by weekly reported hours of video games use to investigate differences between different categories of weekly gaming hours, including a group of participants reporting engaging in 30 or more hours of video game use which represents gamers who meet the criteria for a clinical diagnosis of Internet Gaming Disorder according to the current DSM-5 guidelines. The four resultant groups were as follows:

NG - Non-Gamers (zero reported weekly hours)

CVGE - Casual (low) Video Game Engagement (1-7 hours per week)

RVGE - Recreation (moderate)Video Game Engagement (8-30 hours per week)

AVGE - Addiction Video Game Engagement (30 + hours per week)

Aim 1 Methodology- Evaluate the cross-sectional association between selfreported weekly hours of video game use and the risk for development of metabolic syndrome 
Complex samples binomial linear regression modeling was conducted. To ensure that results were not due to chance, alpha level was set at 0.05 , or a $95 \%$ likelihood that the results found were not due to chance.

The independent variable analyzed was self-reported weekly hours of video game use; the dependent health outcome variables analyzed included: Waist Circumference (WC) measured in centimeters, Triglyceride levels (TGL) measured in mg/dL, HDL cholesterol levels measured in mg/dL, Systolic Blood Pressure (SBP) levels, Fasting Plasma Glucose (FPG) levels measured in mg/dL, and MetS z-score. MetS z-score was calculated utilizing the following gender separated equations recommended by Gurka, Lily, Oliver, \& DeBoer (2014):

For males: $5.4559+0.0125 * \mathrm{WC}$ in $\mathbf{c m}-0.0251 * \mathrm{HDL}$ in $\mathrm{mg} / \mathrm{dL}+0.0047 * \mathrm{SBP}$ in $\mathrm{mmHg}+0.8244 * \ln ($ TGL in $\mathrm{mg} / \mathrm{dL})+0.0106 * \mathrm{FPG}$ in $\mathrm{mg} / \mathrm{dL}$

For Females: $\mathbf{- 7 . 2 5 9 1}+\mathbf{0 . 0 2 5 4} * \mathrm{WC}$ in $\mathbf{c m}-0.0120 * \mathrm{HDL}$ in $\mathrm{mg} / \mathrm{dL}+\mathbf{0 . 0 0 7 5} * \mathrm{SBP}$ in $\mathrm{mmHg}+0.5800 * \ln (\mathrm{TGL}$ in $\mathrm{mg} / \mathrm{dL})+0.0203 *$ FPG in $\mathrm{mg} / \mathrm{Dl}$

Metabolic syndrome severity risk z-scores of $\leq-3.5$, and $\geq 3.5$ were excluded from the linear regression analysis modeling as these scores represent extreme outliers, 13 outlier z-scores were removed.

Life Course Theory postulates that major transitions and turning points taking place during the trajectory from adolescence to adulthood would play a major role on health outcomes. As such the current study controlled for marriage and childbirth on the association between video game use and the development of metabolic syndrome risk. 
Aim 2 Methodology- Evaluate the longitudinal association between self-reported weekly hours of video game use and measures of violence and aggression

To analyze overall violence and aggression scores at the time of wave IV data collection, a violence and aggression involvement scale was developed using 6 items in line with recommendations by researchers Blum, Ireland and Blum, who developed a similar scale using the Add Health wave III data in 2003 (Blum et al., 2003). The items used in the measure included: "In the past 12 months, how often did you use or threaten to use a weapon to get something from someone?", "In the past 12 months, how often did you take part in a physical fight where a group of your friends was against another group?", "In the past 12 months, how often did you get into a serious physical fight?", "In the past 12 months, how often did you hurt someone badly enough in a physical fight that he or she needed care from a doctor or nurse?", "Which of the following things happened in the past 12 months? You pulled a knife or gun on someone.", and "Which of the following things happened in the past 12 months? You shot or stabbed someone". The items were measured on an ordinal scale with response values being: $0=$ never, $1=$ once, $2=$ more than once, $6=$ refused, $8=$ don't know, and $9=$ not applicable. As recommended by Blum and colleagues, the continuous scale for the violence and aggression involvement scale was dichotomized along the 75th percentile.

Cross sectional linear regression analysis modeling was conducted to analyze the correlation between weekly video game use and violence and aggression involvement scores using data collected during wave IV of Add Health. Model fitting information was calculated to indicate the parameters of the model. 1-tailed significance Pearson 
correlation was reported to test whether all the estimated regression coefficients in the model were simultaneously zero. ANOVA were analyzed to test whether at least one of the predictors' regression coefficient is not equal to zero in the model. To ensure that results were not due to chance, alpha level was set at 0.05 , or a $95 \%$ likelihood that the results found were not be due to chance.

Aim 3 Methodology- Evaluate the longitudinal association between self-reported weekly hours of video game use and various mental health outcomes

Logistic regression of weekly hours of video game use at wave I, III, and IV predicting risk for development of metabolic syndrome at wave IV was conducted controlling for Gender, and Race / Ethnicity and Life Course Theory transitional variables of level of education and marriage status.

Variables shown in the literature to contribute to aggression in both males and females in the United States (Ferguson, 2015) were included into the regression model including; having ever been diagnosed with depression in the past, having ever been diagnosed with attention deficit hyper-activity disorder or attention deficit disorder, having ever been diagnosed with post-traumatic stress disorder, having ever been diagnosed with anxiety or panic attacks, and self-reported drug use dichotomized to marijuana use and all other drugs except marijuana. 


\section{CHAPTER IV}

\section{Results}

\section{Descriptive Statistics}

The total sample analyzed in wave IV which met criteria to for the current study was 5,114 participants representative of $21,142,16$ persons living in the United States, with 2,353 (46.01\%) representative of 11,126,185 male and 2,761 (53.99\%) representative of 10,887,852 female respondents. Gender distribution of the Add Health sample is shown in figure 1.

Figure 1. Gender Distribution of the Add Health Sample

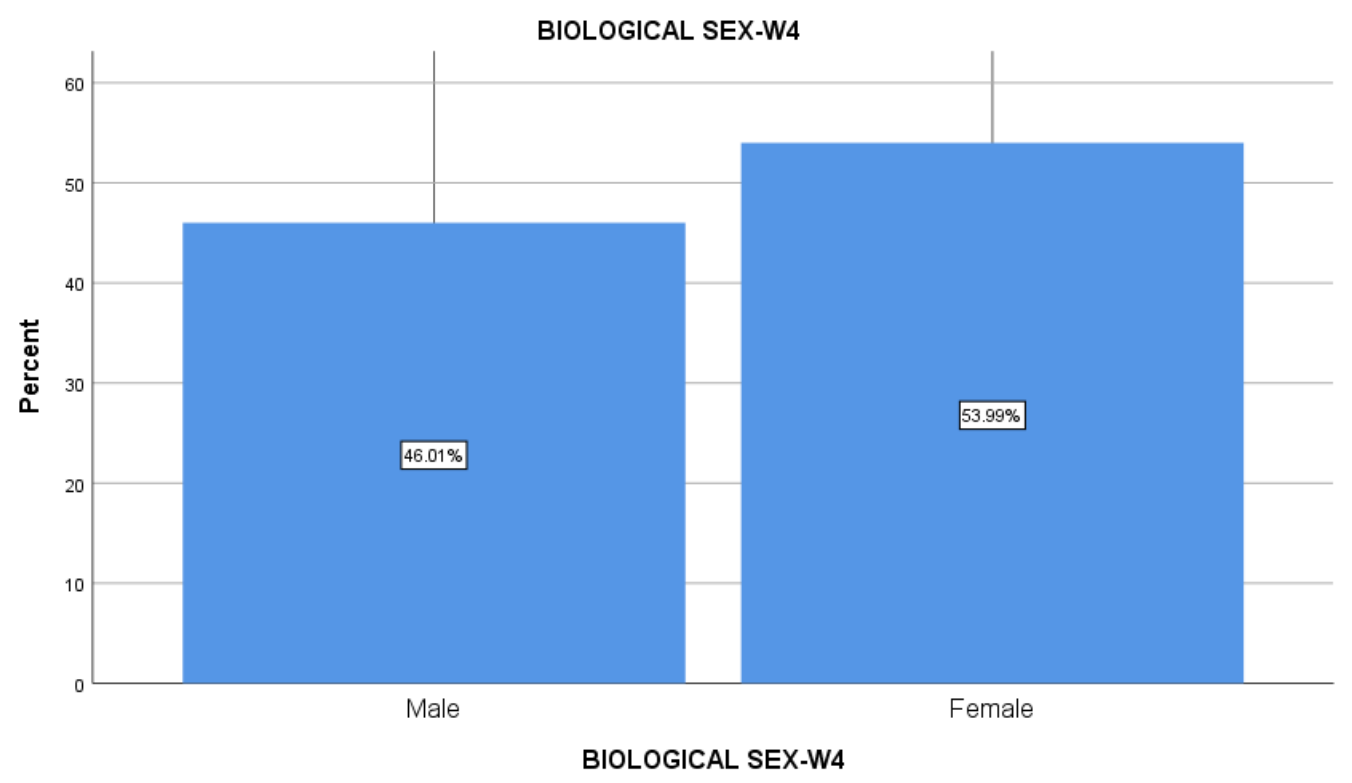

Race and ethnicity demographic frequency analysis of the sample confirmed the Add Health sample is nationally representative of the United States with 3,048 (57.44\%) of participants representing 14,789,182 persons in the United States self-reporting as 
white, $1,127(22.51 \%$ ) participants representing 14,789,182 persons in the United States self-reporting as Black, $519(11.21 \%)$ participants representing 2,375,172 persons in the United States self-reporting as Hispanic only, and 404 (8.79\%) participants representing 1,934,794 persons in the United States self-reporting as other or mixed race. Race and Ethnicity distribution for the Add Health sample is shown in figure 2.

Figure 2. Race and Ethnicity of the Add Health Sample

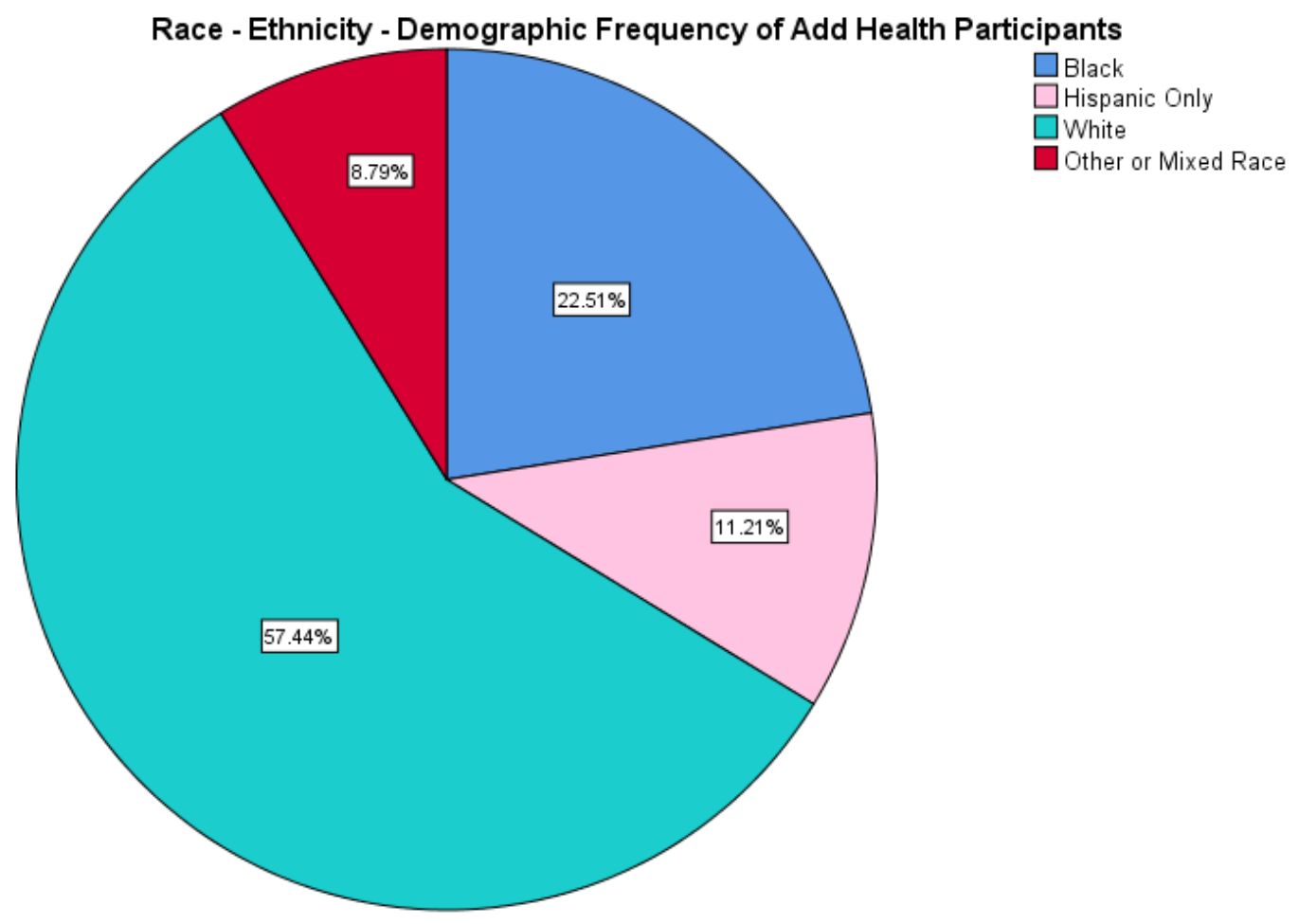


Table 2. Gender and Race / Ethnicity Demographic Characteristics for Add Health Wave IV

\begin{tabular}{llc}
\hline Demographic Category & $\begin{array}{l}\text { Add Health Wave IV } \\
(\mathbf{N = 5 , 1 1 4 )}\end{array}$ & Population Estimate \\
\hline Gender & $2,761(53.99)$ & $10,887,852$ \\
$\quad$ Female $n(\%)$ & $2,353(46.01)$ & $11,126,185$ \\
Male $n(\%)$ & & \\
& & $1,934,794$ \\
Other or Mixed Race $n(\%)$ & $404(8.79)$ & $3,301,024$ \\
Black $n(\%)$ & $1,127(22.51)$ & $2,375,172$ \\
Hispanic Only $n(\%)$ & $519(11.21)$ & $14,789,182$ \\
White $n(\%)$ & $3,048(57.44)$ &
\end{tabular}

Descriptive analysis of weekly hours of video game use showed 2,997 (60.70\%) participants representing 12.7 million persons in the United States reported engaging in zero hours per week of computer or internet game use, with 1,393 (28.22\%) participants representing 6,058,064 having reported 1-7 hours, $482(9.76 \%)$ participants representing 2,104,174 having reported 8-30 hours, and 65 (1.32\%) participants representing 263,205 reported 30 or more hours. Weekly gaming hours groups and respective population estimates at Wave IV are shown in table 3. Weekly gaming hours groups at wave IV are shown in figure 3. 
Table 3. Weekly Gaming Hours Groups and Add Health Population Estimates at Wave IV

\begin{tabular}{|c|c|c|c|c|}
\hline & & $\begin{array}{c}\text { Wave IV } \\
\text { Participants }\end{array}$ & Percent & Population Estimate \\
\hline \multirow{4}{*}{$\begin{array}{l}\text { Weekly } \\
\text { Gaming } \\
\text { Hours }\end{array}$} & 0 hours & 2,997 & $60.70 \%$ & $12,716,725$ \\
\hline & $1-7$ & 1,393 & $28.22 \%$ & $6,058,064$ \\
\hline & $8-30$ & 482 & $9.76 \%$ & $2,104,174$ \\
\hline & $30+$ & 65 & $1.32 \%$ & 263,205 \\
\hline \multicolumn{2}{|l|}{ Total } & 5,114 & 100.0 & $21,142,169$ \\
\hline
\end{tabular}

Figure 3. Weekly Gaming Hours Groups at Wave IV

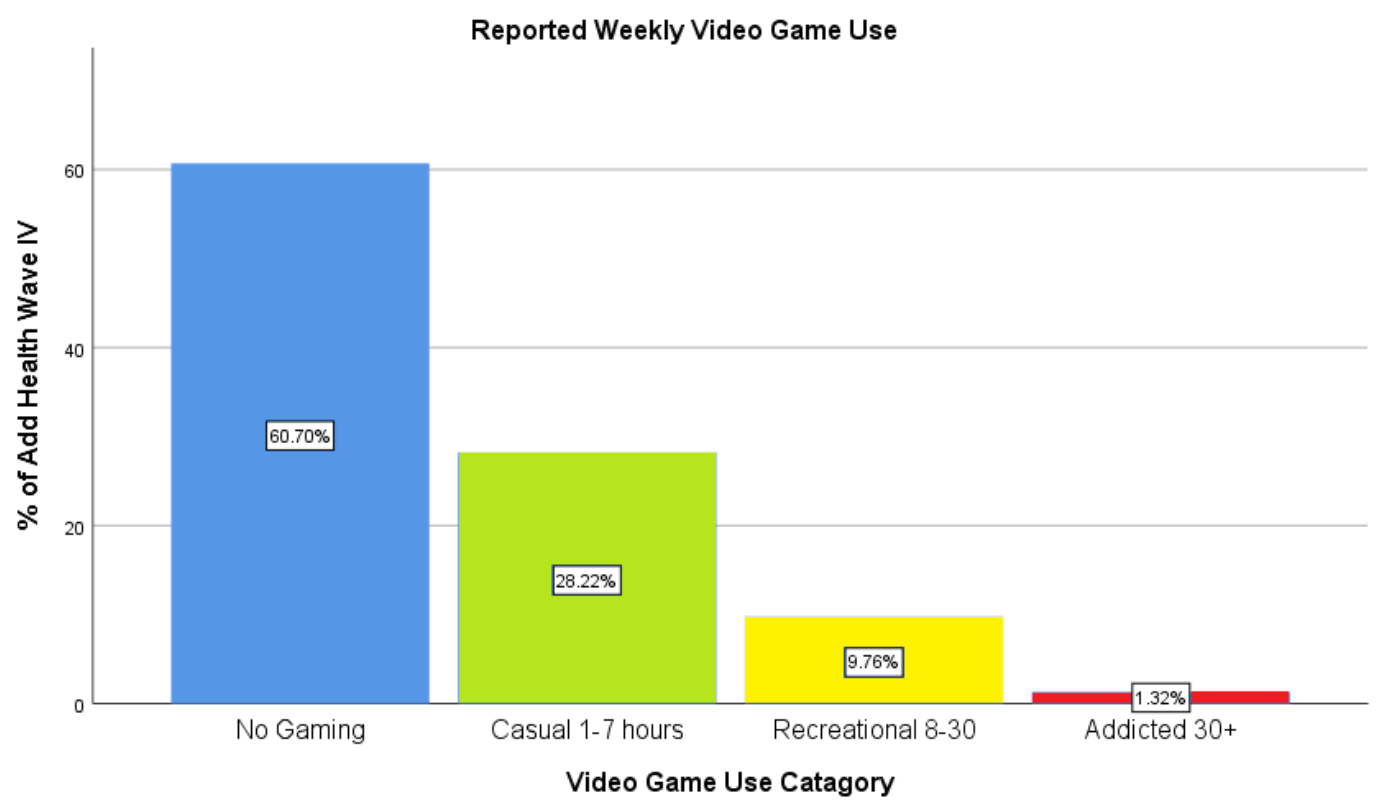


Examining only those who reported using video games, 2,117 participants representing 8,425,443 persons in the United States who reported weekly engagement in video game use, $3.07 \%$ (65) reported engaging in 30 or more hours per week.

\section{Video Game Use Over Time}

To investigate differences in longitudinal trends of adolescents as they develop into adulthood, video game use over time was examined among two intersecting groups; those who reported weekly hours of video game use at wave I or II (gaming group) and those who reported no video game use at wave I or II.

Mixed model linear repeated measures analysis revealed a significant correlation between weekly engagement in video game use across all waves. Those who played during Wave 1 were more likely to play at Wave 2, etc. Interestingly, mean weekly hours of gaming of the total sample went down across every time point except Wave II to III, indicating that participants were engaging the highest levels of video game use during Wave III in which they age ranged from 18 to 26.

\section{Mean Video Game Use Over Time Including Gamers and Non-Gamers}

Mean hours of gaming including gamers and non-gamers at wave $\mathrm{I}(\mathrm{M}=2.775$, $\mathrm{SE}=0.091, \mathrm{CI}=2.596 ; 2.954)$, mean hours of gaming including gamers and non-gamers at wave II $(\mathrm{M}=2.341, \mathrm{SE}=0.084, \mathrm{CI}=2.175 ; 2.506)$, mean hours of gaming including gamers and non-gamers at wave III $(\mathrm{M}=4.788, \mathrm{SE}=0.148, \mathrm{CI}=4.498 ; 5.078)$, and mean hours of gaming including gamers and non-gamers at wave IV $(\mathrm{M}=3.050, \mathrm{SE}=$ $0.114, \mathrm{CI}=2.826 ; 3.273$ ). Mean hours of gaming separated by Add Health wave number is shown in table 4 . 
Table 4. Mean Hours of Gaming Separated by Add Health Wave Number

\begin{tabular}{|l|l|l|l|}
\hline Add Health Wave \# & $\begin{array}{l}\text { Mean Hours of } \\
\text { Gaming }\end{array}$ & Standard Error & $\begin{array}{l}\text { 95\% Confidence } \\
\text { Interval }\end{array}$ \\
\hline 1 & 2.775 & 0.091 & $2.596-2.954$ \\
\hline 2 & 2.341 & 0.084 & $2.175-2.506$ \\
\hline 3 & 4.788 & 0.148 & $4.498-5.078$ \\
\hline 4 & 3.050 & 0.114 & $2.826-3.273$ \\
\hline
\end{tabular}

Figure 4. Gaming Over Time Including Non-Gamers

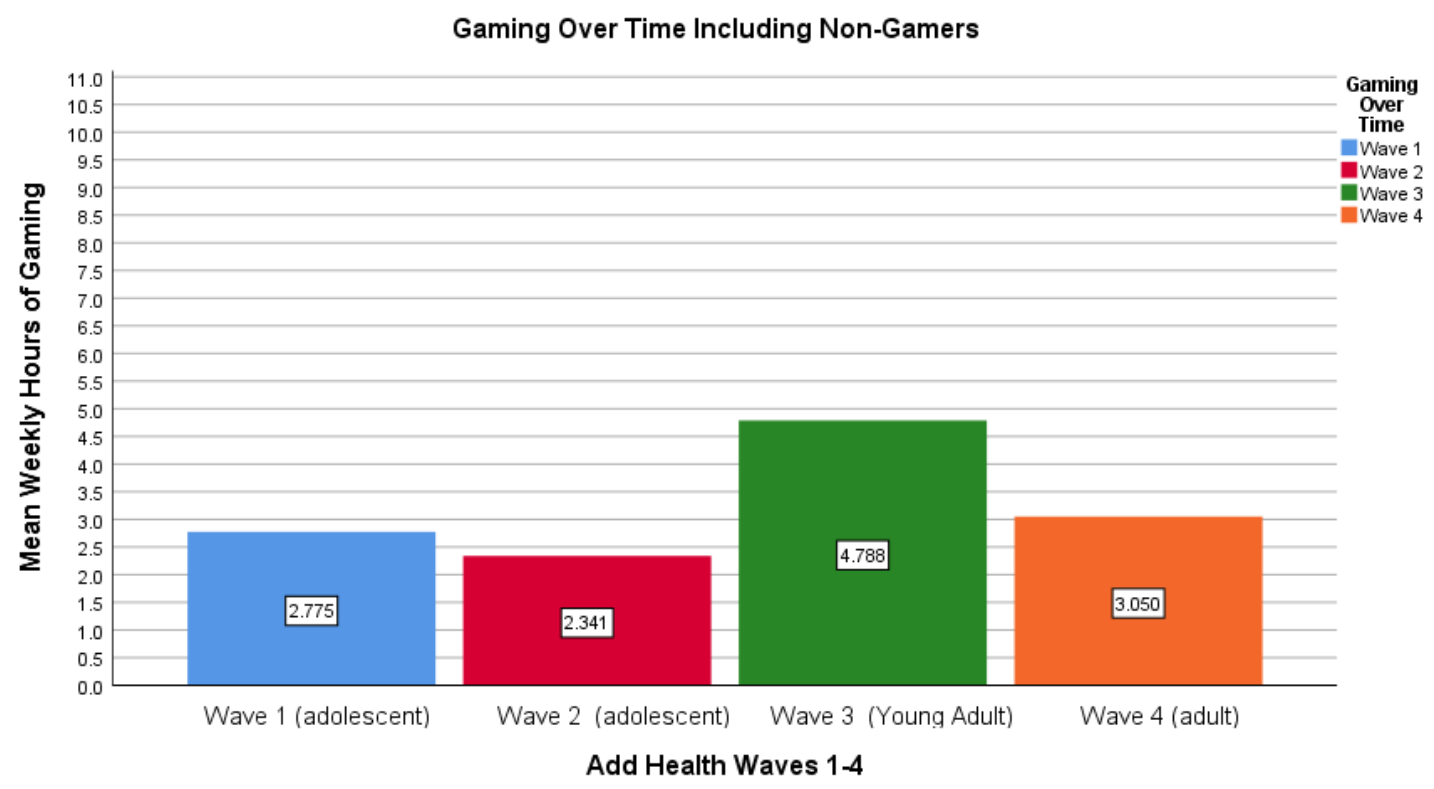

The estimates of fixed effects indicated that weekly hours of gaming at wave I $(\mathrm{t}$ $=-1.906, \mathrm{CI}=-0.556780 ; 0.007795, \mathrm{p}=0.057)$, gaming at Wave II $(\mathrm{t}=-5.204, \mathrm{CI}=-$ $0.976074 ;-0.441931, \mathrm{p}<0.001)$, and gaming at Wave III $(\mathrm{t}=-10.870, \mathrm{CI}=1.425076$; 2.052139, $\mathrm{p}<0.001)$ were significantly associated with weekly hours of gaming at Wave IV in both gamers and non-gamers. The results of the estimates of fixed effects are shown in table 5 . 
Table 5. Estimates of Fixed Effects Table for Weekly Hours of Gaming Over Time

\begin{tabular}{|l|l|l|l|l|l|}
\hline $\begin{array}{l}\text { Add Health } \\
\text { Wave \# }\end{array}$ & Estimate & $\begin{array}{l}\text { Standard } \\
\text { Error }\end{array}$ & $\mathrm{t}$ & Significance & $\begin{array}{l}95 \% \\
\text { Confidence } \\
\text { Interval }\end{array}$ \\
\hline Intercept & 3.049668 & 0.113947 & 26.764 & .000 & $\begin{array}{l}2.826282- \\
3.273054\end{array}$ \\
\hline 1 & -0.274493 & 0.144009 & -1.906 & .057 & $\begin{array}{l}-0.55678- \\
0.007795\end{array}$ \\
\hline 2 & -0.709003 & 0.136244 & -5.204 & .000 & $\begin{array}{l}-0.976074-- \\
0.441931\end{array}$ \\
\hline 3 & 1.738607 & 0.159939 & 10.870 & .000 & $\begin{array}{l}1.425076- \\
2.052139\end{array}$ \\
\hline
\end{tabular}

\section{Mean Video Game Use Over Time - Gamers Only}

Mean hours of gaming among participants who reported any gaming (gamers only $)$ at wave $\mathrm{I}(\mathrm{M}=7.459, \mathrm{SE}=0.249, \mathrm{CI}=6.97 ; 7.948)$, mean hours of gaming of gamers only at wave II $(\mathrm{M}=7.23, \mathrm{SE}=0.209, \mathrm{CI}=6.82 ; 7.640)$, mean hours of gaming of gamers only at wave III $(\mathrm{M}=4.526, \mathrm{SE}=.150, \mathrm{CI}=4.231 ; 4.822)$, and mean hours of gaming of gamers only at wave IV $(\mathrm{M}=5.126, \mathrm{SE}=0.156, \mathrm{CI}=4.82 ; 5.432)$. $)$. Mean hours of gaming separated by Add Health wave number only for those who reported time spent playing video games is shown in table 6 .

Table 6. Mean Hours of Gaming for Gamers Only Separated by Add Health Wave Number

\begin{tabular}{|l|l|l|l|}
\hline Add Health Wave \# & $\begin{array}{l}\text { Mean Hours of } \\
\text { Gaming }\end{array}$ & Standard Error & $\begin{array}{l}\text { 95\% Confidence } \\
\text { Interval }\end{array}$ \\
\hline 1 & 7.459 & 0.249 & $6.970-7.948$ \\
\hline 2 & 7.230 & 0.209 & $6.820-7.640$ \\
\hline 3 & 4.526 & 0.150 & $4.231-4.822$ \\
\hline 4 & 5.126 & 0.156 & $4.820-5.432$ \\
\hline
\end{tabular}


Figure 5. Mean Hours of Gaming for Gamers Only Separated by Add Health Wave Number

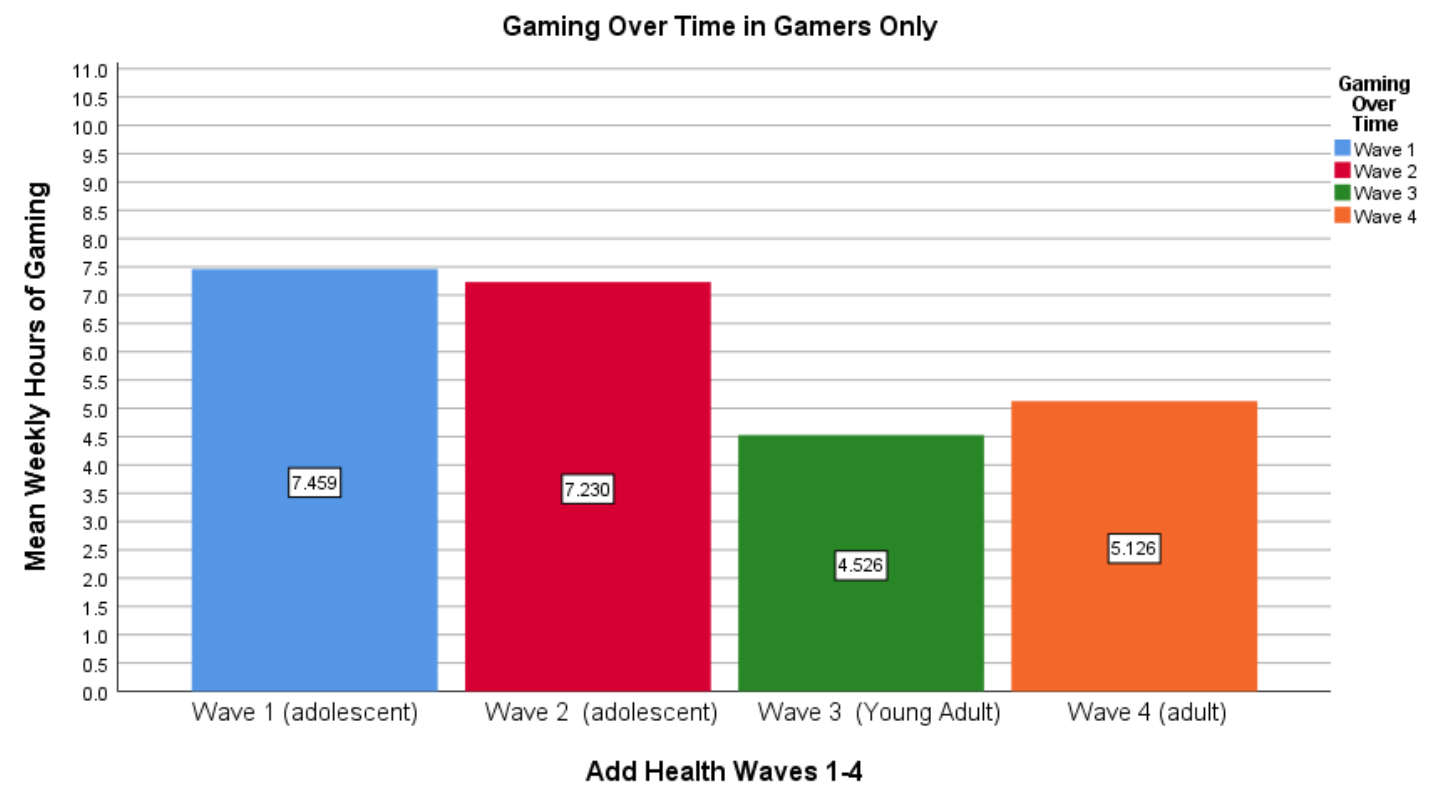

The estimates of fixed effects shows weekly hours of gaming at wave I $(t=7.973$, $\mathrm{CI}=4.820327 ; 5.431529, \mathrm{p}<0.001)$, gaming at Wave $\mathrm{II}(\mathrm{t}=8.252, \mathrm{CI}=1.604162 ;$

2.603847, $\mathrm{p}<0.001)$, and gaming at Wave III $(\mathrm{t}=-3.053, \mathrm{CI}=-0.984519 ;-0.214497, \mathrm{p}=$ 0.002) were significantly associated with weekly hours of gaming at Wave IV in gamers only. The results of the estimates of fixed effects for those who reported any gaming are shown in table 6. 
Table 7. Estimates of Fixed Effects for Gamers Only

\begin{tabular}{|l|l|l|l|l|l|}
\hline $\begin{array}{l}\text { Add Health } \\
\text { Wave \# }\end{array}$ & Estimate & $\begin{array}{l}\text { Standard } \\
\text { Error }\end{array}$ & $\mathrm{t}$ & Significance & $\begin{array}{l}95 \% \\
\text { Confidence } \\
\text { Interval }\end{array}$ \\
\hline Intercept & 5.125928 & 0.155855 & 32.889 & .000 & $\begin{array}{l}4.820327- \\
5.431529\end{array}$ \\
\hline 1 & 2.333330 & 0.292663 & 7.973 & .000 & $\begin{array}{l}1.759520- \\
2.907139\end{array}$ \\
\hline 2 & 2.104005 & 0.254966 & 8.252 & .000 & $\begin{array}{l}1.604162- \\
2.603847\end{array}$ \\
\hline 3 & -0.599508 & 0.196372 & -3.053 & .002 & $\begin{array}{l}-0.984519-- \\
0.214497\end{array}$ \\
\hline
\end{tabular}

Aim 1 Results - Evaluate the cross-sectional association between self-reported weekly hours of video game use and the risk for development of metabolic syndrome

Of the 5,114 participants analyzed in the sample, 3,484 had valid measurements in all five biomarker categories (Waist Circumference, Systolic Blood Pressure, Blood Glucose, HDL, and total Triglycerides) to calculate metabolic risk severity $\mathrm{Z}$ scores. MetS z-scores among the total sample displayed normal distribution: Median $(\mathrm{Mdn})=$ 0.8953 and Mean $(\mathrm{Mn})$ 0.0872. There was a statistically significant difference, $\mathrm{p}<0.001$ between males $(\mathrm{Mdn}=0.9505, \mathrm{Mn}=0.0774)$ and females $(\mathrm{Mdn}=0.8549, \mathrm{Mn}=0.0946)$, with females reporting slightly higher overall mean metabolic risk severity z-scores than males in One-Sample T-Test. The overall MetS z-score distribution for Add Health wave IV participants is shown in figure 6. Metabolic Syndrome risk severity z-score, MetS zscore components, and demographic characteristics for Add Health Wave IV are shown in table 8 . 
Figure 6. Overall Distribution of Met-S z-scores for Add Health at Wave IV

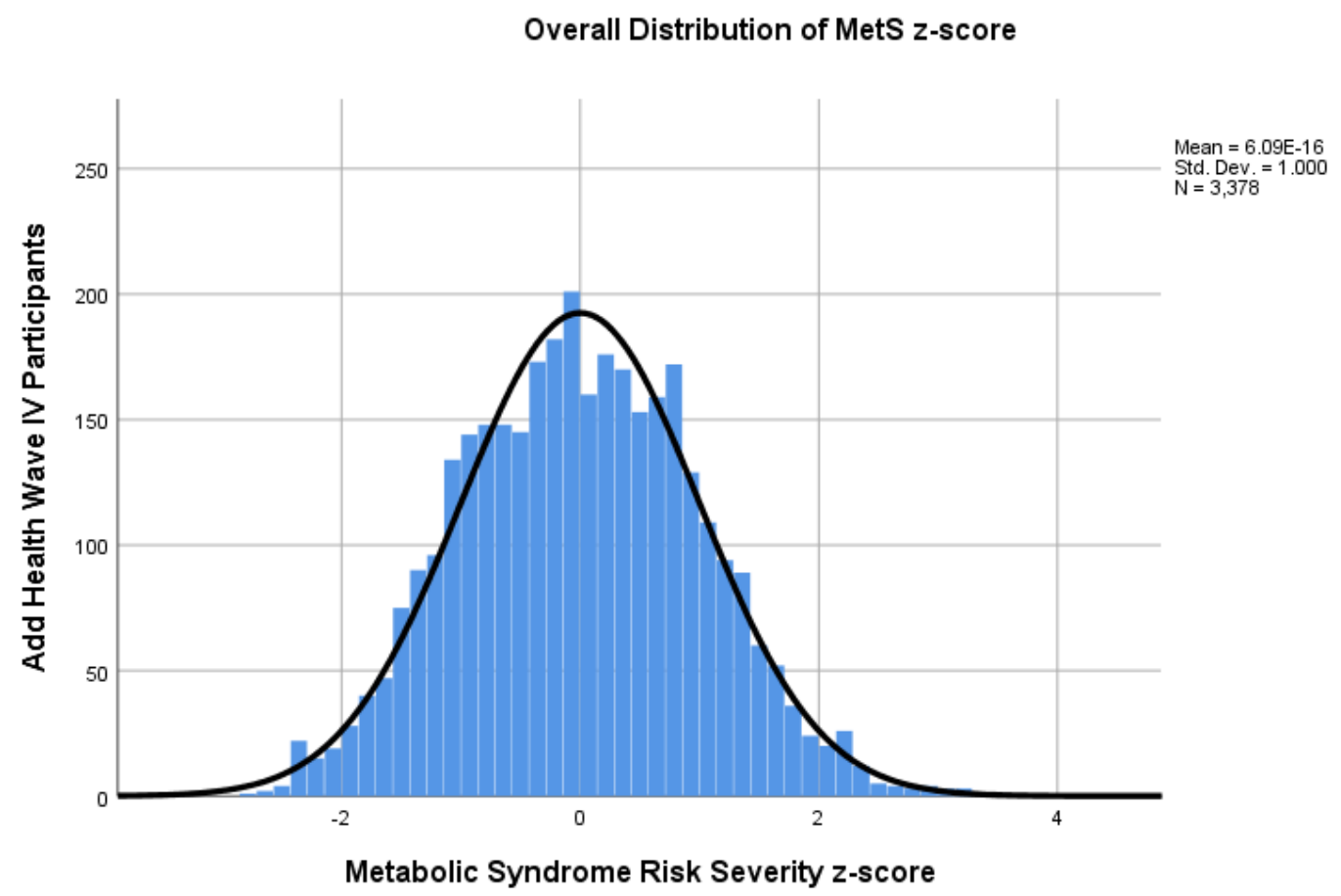

Table 8. Metabolic Syndrome Risk Severity z-score, MetS z-score Components, and Demographic Characteristics for Add Health Wave IV

\section{Biomarker Variable}

Waist Circumference $(\mathrm{cm})(M n+S D)$

Total Triglycerides $(\mathrm{mg} / \mathrm{dL})(M n \pm S D)$

$\mathrm{HDL}(\mathrm{mg} / \mathrm{dL})(M n \pm S D)$

Fasting Plasma Glucose $(\mathrm{mg} / \mathrm{dL})(M n+S D)$

Systolic Blood Pressure $(\mathrm{mm} \mathrm{Hg})(M n \pm S D)$

Mean MetS z-score $(M n \pm S D)$

Males $(M n+S D)$

Females $(M n+S D)$
Add Health Wave IV $(\mathrm{N}=\mathbf{5 , 1 1 4})$

$106.67 \pm(1.22)$

$248.96 \pm 109.83$

$47.85 \pm 15.77$

$142.61 \pm 176.3$

$139.6 \pm 114.8$

$0.0872 \pm 0.67$

$0.0774 \pm 0.42$

$0.0946+0.47$ 


\section{Wave IV - Cross-Sectional}

Table 9. Logistic Regression of Weekly Hours of Gaming at Wave IV Predicting Risk for Development of Metabolic Syndrome at Wave IV $(n=3,315)$

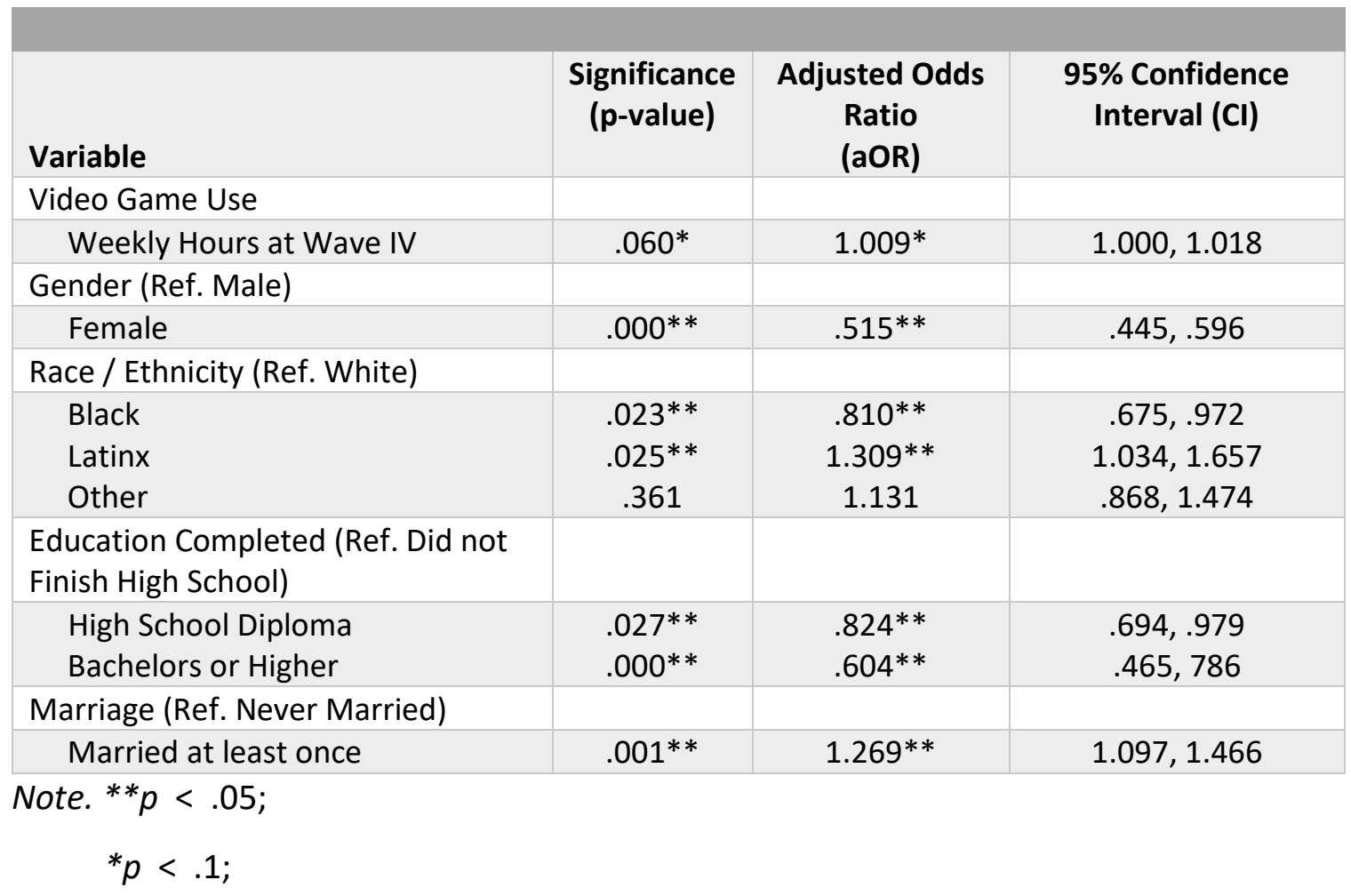




\section{Wave I to IV}

Table 10. Logistic Regression of Weekly Hours of Gaming at Wave I Predicting Risk for Development of Metabolic Syndrome at Wave IV $(n=3,314)$

\begin{tabular}{|l|c|c|c|}
\hline & $\begin{array}{c}\text { Significance } \\
\text { (p-value) }\end{array}$ & $\begin{array}{c}\text { Adjusted Odds } \\
\text { Ratio } \\
\text { (aOR) }\end{array}$ & $\begin{array}{c}95 \% \text { Confidence } \\
\text { Interval (C) }\end{array}$ \\
\hline $\begin{array}{l}\text { Variable } \\
\text { Video Game Use }\end{array}$ & $.034^{* *}$ & $1.012^{* *}$ & $1.001,1.024$ \\
\hline $\begin{array}{l}\text { Weekly Hours at Wave I } \\
\text { Gender (Ref. Male) }\end{array}$ & $.000^{* *}$ & $.532^{* *}$ & $.460, .615$ \\
\hline $\begin{array}{l}\text { Female } \\
\text { Race / Ethnicity (Ref. White) }\end{array}$ & $.023^{* *}$ & $.810^{* *}$ & $.675, .972$ \\
\hline $\begin{array}{l}\text { Black } \\
\text { Latinx } \\
\text { Other }\end{array}$ & $.025^{* *}$ & $1.305^{* *}$ & $1.033,1.647$ \\
\hline $\begin{array}{l}\text { Education Completed (Ref. Did not } \\
\text { Finish High School) }\end{array}$ & .386 & 1.123 & $.864,1.458$ \\
\hline $\begin{array}{l}\text { High School Diploma } \\
\text { Bachelors or Higher }\end{array}$ & $.049^{* *}$ & & $.845^{* *}$ \\
\hline $\begin{array}{l}\text { Marriage (Ref. Never Married) } \\
\text { Married at least once }\end{array}$ & $.000^{* *}$ & $.614^{* *}$ & $.715, .999$ \\
\hline $\begin{array}{l}\text { Note. }{ }^{* *} p<.05 ; \\
\quad * p<.1 ;\end{array}$ & $.003^{* *}$ & $1.241^{* *}$ & $.473,796$ \\
\hline
\end{tabular}


Aim 2 Results - Evaluate the longitudinal association between self-reported weekly hours of video game use and measures of violence and aggression

\section{Wave IV Cross-Sectional}

Table 11. Logistic Regression of Weekly Hours of Gaming at Wave IV Predicting Overall Violence and Aggression Scores at Wave IV $(n=3,251)$

\begin{tabular}{|c|c|c|c|}
\hline Variable & $\begin{array}{l}\text { Significance } \\
\text { (p-value) }\end{array}$ & $\begin{array}{c}\text { Adjusted Odds } \\
\text { Ratio } \\
\text { (aOR) }\end{array}$ & $\begin{array}{l}\text { 95\% Confidence } \\
\text { Interval (Cl) }\end{array}$ \\
\hline \multicolumn{4}{|l|}{ Video Game Use } \\
\hline Weekly Hours at Wave IV & .266 & 1.007 & $.995,1.020$ \\
\hline \multicolumn{4}{|l|}{ Gender (Ref. Male) } \\
\hline Female & $.000 * *$ & $.313^{* *}$ & $.234, .418$ \\
\hline \multicolumn{4}{|l|}{ Race / Ethnicity (Ref. White) } \\
\hline Black & $.000 * *$ & $1.980 * *$ & $1.436,2.730$ \\
\hline Latin $x$ & $.000 * *$ & $2.123 * *$ & $1.441,3.130$ \\
\hline Other & $.029 * *$ & $1.694 * *$ & $1.054,2.721$ \\
\hline \multicolumn{4}{|c|}{$\begin{array}{l}\text { Education Completed (Ref. Did not } \\
\text { Finish High School) }\end{array}$} \\
\hline $\begin{array}{l}\text { High School Diploma } \\
\text { Bachelors or Higher }\end{array}$ & $\begin{array}{l}.000 * * \\
.000 * *\end{array}$ & $\begin{array}{l}.457^{* *} \\
.168^{* *}\end{array}$ & $\begin{array}{l}.347, .602 \\
.081, .352\end{array}$ \\
\hline \multicolumn{4}{|l|}{ Marriage (Ref. Never Married) } \\
\hline Married at least once & $.058 *$ & $.766^{*}$ & $.581,1.009$ \\
\hline
\end{tabular}

Note. ${ }^{* *} p<.05$;

$$
{ }^{*} p<.1
$$




\section{Wave III to IV}

Table 12. Logistic Regression of Weekly Hours of Gaming at Wave III Predicting Overall Violence and Aggression Scores at Wave IV $(n=2,748)$

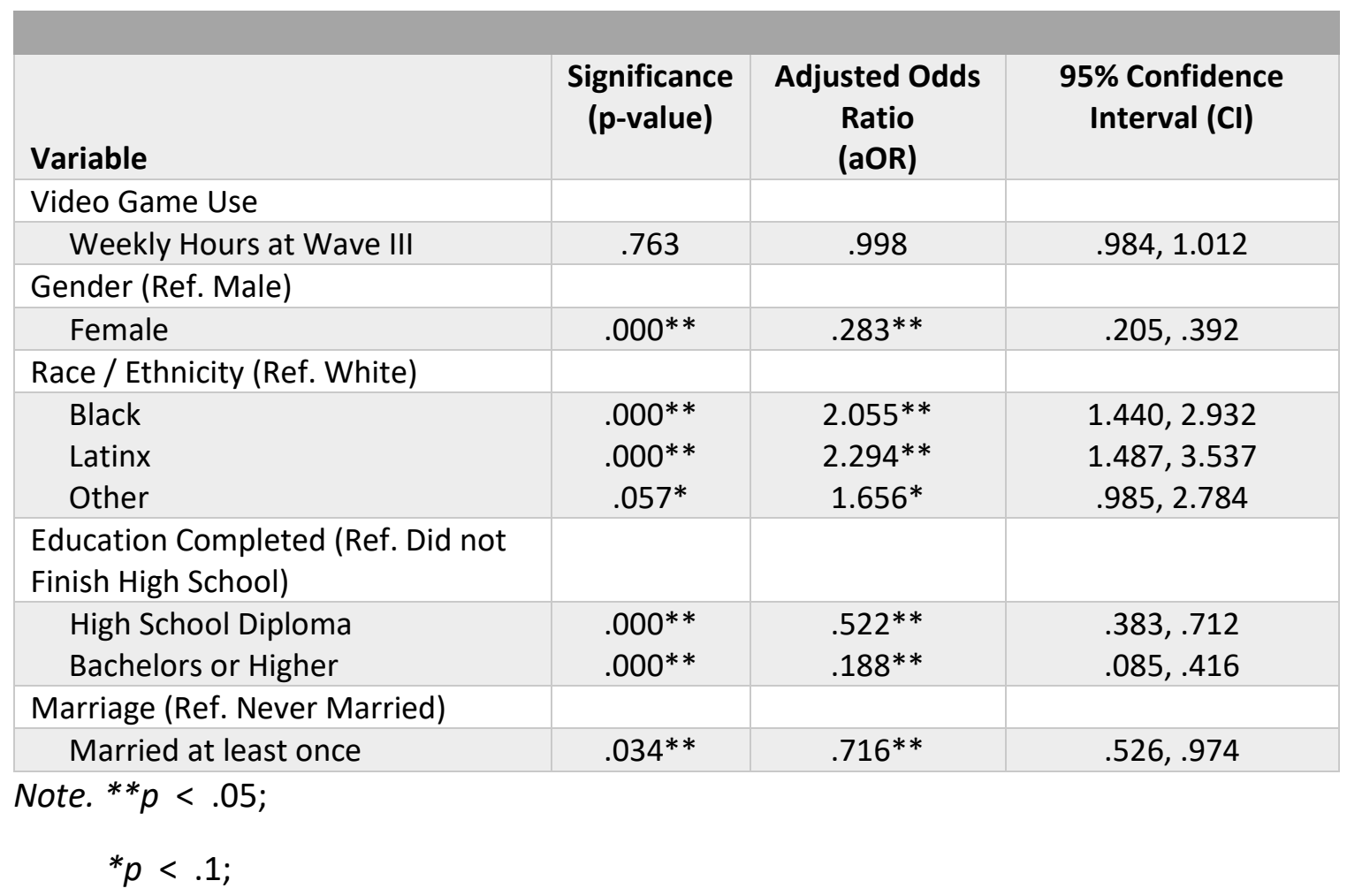




\section{Wave I to IV}

Table 13. Logistic Regression of Weekly Hours of Gaming at Wave I Predicting Overall Violence and Aggression Scores at Wave IV $(n=3,332)$

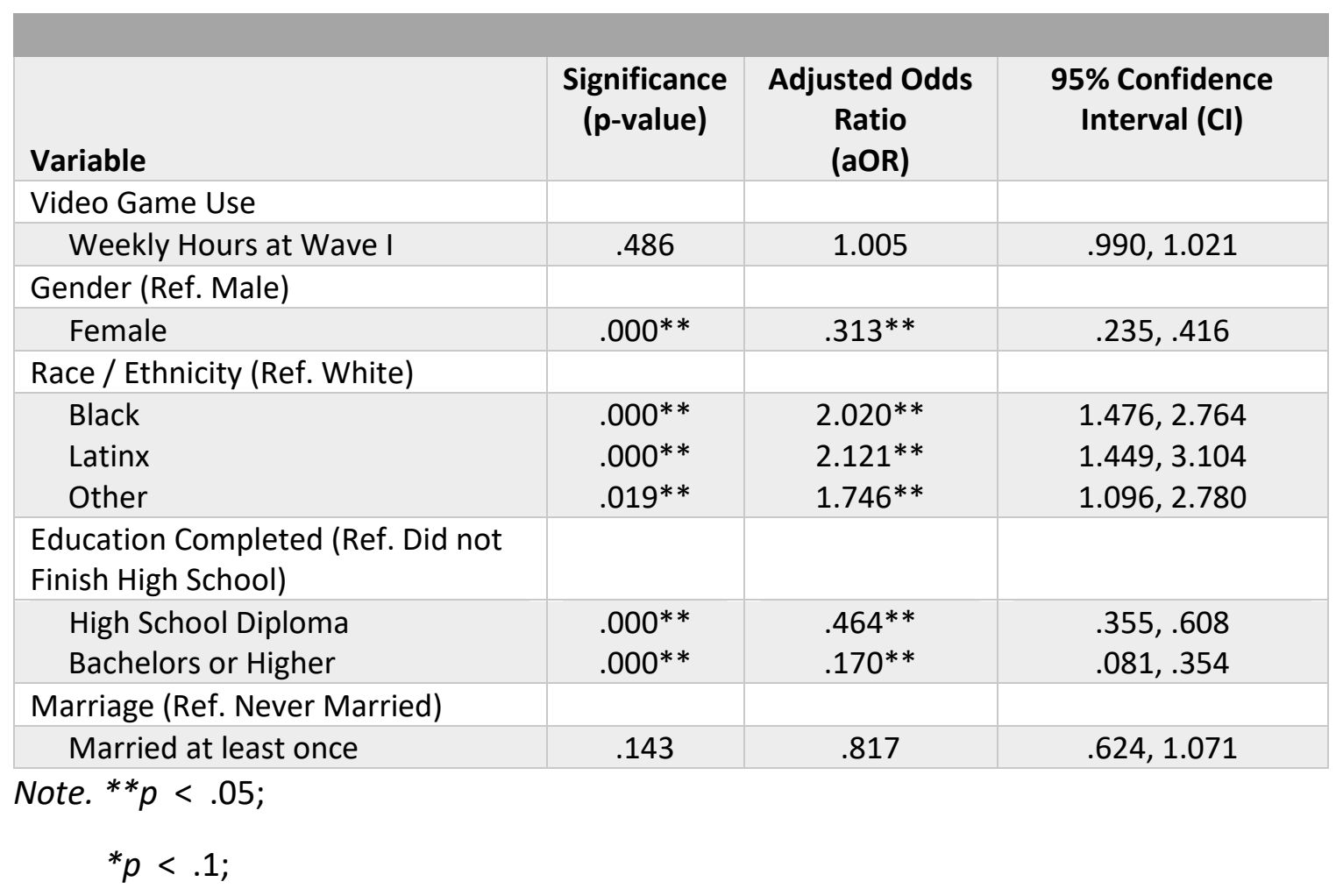


Aim 3 Results- Evaluate the longitudinal association between self-reported weekly hours of video game use and various mental health outcomes

\section{Sleep Problems}

\section{Wave III to IV}

Table 14. Logistic Regression of Weekly Hours of Gaming at Wave III Predicting Sleep Problems at Wave IV $(n=2,723)$

\begin{tabular}{|c|c|c|c|}
\hline Variable & $\begin{array}{l}\text { Significance } \\
\text { (p-value) }\end{array}$ & $\begin{array}{l}\text { Adjusted Odds } \\
\text { Ratio } \\
\text { (aOR) }\end{array}$ & $\begin{array}{l}\text { 95\% Confidence } \\
\text { Interval (CI) }\end{array}$ \\
\hline \multicolumn{4}{|l|}{ Video Game Use } \\
\hline Weekly Hours at Wave III & .391 & 1.004 & $.995,1.013$ \\
\hline \multicolumn{4}{|l|}{ Gender (Ref. Male) } \\
\hline Female & $.000 * *$ & $1.525 * *$ & $1.289,1.805$ \\
\hline \multicolumn{4}{|l|}{ Race / Ethnicity (Ref. White) } \\
\hline $\begin{array}{l}\text { Black } \\
\text { Latinx } \\
\text { Other }\end{array}$ & $\begin{array}{l}.023 * * \\
.378 \\
.109\end{array}$ & $\begin{array}{l}.810 * * \\
.883 \\
1.296\end{array}$ & $\begin{array}{l}.675, .972 \\
.670,1.164 \\
.944,1.780\end{array}$ \\
\hline \multicolumn{4}{|c|}{$\begin{array}{l}\text { Education Completed (Ref. Did not } \\
\text { Finish High School) }\end{array}$} \\
\hline $\begin{array}{l}\text { High School Diploma } \\
\text { Bachelors or Higher }\end{array}$ & $\begin{array}{l}.157 \\
.078 *\end{array}$ & $\begin{array}{c}1.152 \\
1.310^{*}\end{array}$ & $\begin{array}{l}.947,1.401 \\
.970,1.768\end{array}$ \\
\hline \multicolumn{4}{|l|}{ Marriage (Ref. Never Married) } \\
\hline Married at least once & $.002 * *$ & $.769 * *$ & $.650, .910$ \\
\hline
\end{tabular}




\section{Wave IV Cross-Sectional}

Table 15. Logistic Regression of Weekly Hours of Gaming at Wave IV Predicting Sleep Problems at Wave IV $(n=3,227)$

\begin{tabular}{|c|c|c|c|}
\hline Variable & $\begin{array}{l}\text { Significance } \\
\text { (p-value) }\end{array}$ & $\begin{array}{l}\text { Adjusted Odds } \\
\text { Ratio } \\
\text { (aOR) }\end{array}$ & $\begin{array}{l}\text { 95\% Confidence } \\
\text { Interval (CI) }\end{array}$ \\
\hline \multicolumn{4}{|l|}{ Video Game Use } \\
\hline Weekly Hours at Wave IV & $.002 * *$ & $1.018^{*}$ & $1.007,1.029$ \\
\hline \multicolumn{4}{|l|}{ Gender (Ref. Male) } \\
\hline Female & $.000 * *$ & $1.662 * *$ & $1.424,1.940$ \\
\hline \multicolumn{4}{|l|}{ Race / Ethnicity (Ref. White) } \\
\hline $\begin{array}{l}\text { Black } \\
\text { Latinx } \\
\text { Other }\end{array}$ & $\begin{array}{l}.000 * * \\
.376 \\
.346\end{array}$ & $\begin{array}{l}.599 * * \\
.894 \\
1.153\end{array}$ & $\begin{array}{l}.496, .723 \\
.697,1.146 \\
.857,1.551\end{array}$ \\
\hline \multicolumn{4}{|c|}{$\begin{array}{l}\text { Education Completed (Ref. Did not } \\
\text { Finish High School) }\end{array}$} \\
\hline $\begin{array}{l}\text { High School Diploma } \\
\text { Bachelors or Higher }\end{array}$ & $\begin{array}{l}.413 \\
.112\end{array}$ & $\begin{array}{l}.1 .078 \\
.1 .257\end{array}$ & $\begin{array}{l}.900,1.292 \\
.948,1.669\end{array}$ \\
\hline \multicolumn{4}{|l|}{ Marriage (Ref. Never Married) } \\
\hline Married at least once & $.001 * *$ & $.772^{* *}$ & $.661, .901$ \\
\hline
\end{tabular}




\section{Depression}

\section{Wave III to IV}

Table 16. Logistic Regression of Weekly Hours of Gaming at Wave III Predicting Depression Diagnoses at Wave IV $(n=2,748)$

\begin{tabular}{|c|c|c|c|}
\hline Variable & $\begin{array}{l}\text { Significance } \\
\text { (p-value) }\end{array}$ & $\begin{array}{l}\text { Adjusted Odds } \\
\text { Ratio } \\
\text { (aOR) }\end{array}$ & $\begin{array}{l}\text { 95\% Confidence } \\
\text { Interval }(\mathrm{Cl})\end{array}$ \\
\hline \multicolumn{4}{|l|}{ Video Game Use } \\
\hline Weekly Hours at Wave III & $.053^{*}$ & 1.010 & $1.000,1.019$ \\
\hline \multicolumn{4}{|l|}{ Gender (Ref. Male) } \\
\hline Female & $.000 * *$ & $2.888^{* *}$ & $2.277,3.663$ \\
\hline \multicolumn{4}{|l|}{ Race / Ethnicity (Ref. White) } \\
\hline Black & $.000 * *$ & $.390 * *$ & $.286, .532$ \\
\hline Latin $x$ & $.004 * *$ & $.565^{* *}$ & $.384, .831$ \\
\hline Other & $.083 *$ & .718 & $.493,1.044$ \\
\hline \multicolumn{4}{|c|}{$\begin{array}{l}\text { Education Completed (Ref. Did not } \\
\text { Finish High School) }\end{array}$} \\
\hline High School Diploma & .770 & 1.039 & $.803,1.345$ \\
\hline Bachelors or Higher & .193 & .771 & $.521,1.141$ \\
\hline \multicolumn{4}{|l|}{ Marriage (Ref. Never Married) } \\
\hline Married at least once & .899 & 1.014 & $.820,1.253$ \\
\hline
\end{tabular}




\section{Wave IV Cross-Sectional}

Table 17. Logistic Regression of Weekly Hours of Gaming at Wave IV Predicting Depression Diagnoses at Wave IV $(n=3,250)$

\begin{tabular}{|c|c|c|c|}
\hline Variable & $\begin{array}{c}\text { Significance } \\
\text { (p-value) }\end{array}$ & $\begin{array}{c}\text { Adjusted Odds } \\
\text { Ratio } \\
\text { (aOR) }\end{array}$ & $\begin{array}{l}\text { 95\% Confidence } \\
\text { Interval (Cl) }\end{array}$ \\
\hline \multicolumn{4}{|l|}{ Video Game Use } \\
\hline Weekly Hours at Wave IV & $.006^{* *}$ & $1.016 * *$ & $1.005,1.027$ \\
\hline \multicolumn{4}{|l|}{ Gender (Ref. Male) } \\
\hline Female & $.000 * *$ & $2.760 * *$ & $2.228,3.420$ \\
\hline \multicolumn{4}{|l|}{ Race / Ethnicity (Ref. White) } \\
\hline Black & $.000 * *$ & $.402 * *$ & $.303, .533$ \\
\hline Latin $x$ & $.003 * *$ & $.608^{* *}$ & $.436, .847$ \\
\hline Other & $.080 *$ & $.728^{*}$ & $.511,1.038$ \\
\hline \multicolumn{4}{|c|}{$\begin{array}{l}\text { Education Completed (Ref. Did not } \\
\text { Finish High School) }\end{array}$} \\
\hline High School Diploma & .817 & 1.028 & $.814,1.297$ \\
\hline Bachelors or Higher & .174 & .777 & $.540,1.118$ \\
\hline \multicolumn{4}{|l|}{ Marriage (Ref. Never Married) } \\
\hline Married at least once & .804 & .976 & $.804,1.184$ \\
\hline
\end{tabular}




\section{Attention Deficit Disorder / Attention Deficit Hyperactivity Disorder \\ Wave III to IV}

Table 18. Logistic Regression of Weekly Hours of Gaming at Wave III Predicting ADD

/ADHD Diagnoses at Wave IV $(n=2,748)$

\begin{tabular}{|c|c|c|c|}
\hline Variable & $\begin{array}{l}\text { Significance } \\
\text { (p-value) }\end{array}$ & $\begin{array}{c}\text { Adjusted Odds } \\
\text { Ratio } \\
\text { (aOR) }\end{array}$ & $\begin{array}{l}\text { 95\% Confidence } \\
\text { Interval (CI) }\end{array}$ \\
\hline \multicolumn{4}{|l|}{ Video Game Use } \\
\hline Weekly Hours at Wave III & .618 & 1.004 & $.988,1.021$ \\
\hline \multicolumn{4}{|l|}{ Gender (Ref. Male) } \\
\hline Female & $.002 * *$ & $.578^{* *}$ & $.406, .824$ \\
\hline \multicolumn{4}{|l|}{ Race / Ethnicity (Ref. White) } \\
\hline Black & $.000 * *$ & $.143^{* *}$ & $.066, .311$ \\
\hline Latin $x$ & $.003 * *$ & $.314^{* *}$ & $.144, .682$ \\
\hline Other & $.011^{* *}$ & $.361^{* *}$ & $.165, .788$ \\
\hline \multicolumn{4}{|c|}{$\begin{array}{l}\text { Education Completed (Ref. Did not } \\
\text { Finish High School) }\end{array}$} \\
\hline High School Diploma & .871 & .967 & $.646,1.448$ \\
\hline Bachelors or Higher & $.011^{* *}$ & .318 & $.131, .770$ \\
\hline \multicolumn{4}{|l|}{ Marriage (Ref. Never Married) } \\
\hline Married at least once & .129 & .763 & $.538,1.082$ \\
\hline
\end{tabular}

Note. $* * p<.05$

$$
* p<.1
$$




\section{Wave IV Cross-Sectional}

Table 19. Logistic Regression of Weekly Hours of Gaming at Wave IV Predicting ADD /ADHD Diagnoses at Wave IV $(n=3,250)$

\begin{tabular}{|c|c|c|c|}
\hline Variable & $\begin{array}{c}\text { Significance } \\
\text { (p-value) }\end{array}$ & $\begin{array}{l}\text { Adjusted Odds } \\
\text { Ratio } \\
\text { (aOR) }\end{array}$ & $\begin{array}{l}\text { 95\% Confidence } \\
\text { Interval (Cl) }\end{array}$ \\
\hline \multicolumn{4}{|l|}{ Video Game Use } \\
\hline Weekly Hours at Wave IV & .358 & 1.008 & $.992,1.024$ \\
\hline \multicolumn{4}{|l|}{ Gender (Ref. Male) } \\
\hline Female & $.001 * *$ & $.564 * *$ & .468 .780 \\
\hline \multicolumn{4}{|l|}{ Race / Ethnicity (Ref. White) } \\
\hline Black & $.000 * *$ & $.178^{* *}$ & $.093, .342$ \\
\hline Latinx & $.000 * *$ & $.251 * *$ & $.116, .542$ \\
\hline Other & $.053^{*}$ & $.537 *$ & $.286,1.009$ \\
\hline \multicolumn{4}{|c|}{$\begin{array}{l}\text { Education Completed (Ref. Did not } \\
\text { Finish High School) }\end{array}$} \\
\hline High School Diploma & .900 & .977 & $.679,1.407$ \\
\hline Bachelors or Higher & $.008 * *$ & .329 & $.146, .744$ \\
\hline \multicolumn{4}{|l|}{ Marriage (Ref. Never Married) } \\
\hline Married at least once & .257 & .832 & $.606,1.143$ \\
\hline
\end{tabular}




\section{Anxiety / Panic Attacks}

\section{Wave III to IV}

Table 20. Logistic Regression of Weekly Hours of Gaming at Wave III Predicting Having been Diagnosed with Anxiety / Panic Attacks Diagnoses at Wave IV $(n=2,748)$

\begin{tabular}{|c|c|c|c|}
\hline Variable & $\begin{array}{l}\text { Significance } \\
\text { (p-value) }\end{array}$ & $\begin{array}{l}\text { Adjusted Odds } \\
\text { Ratio } \\
\text { (aOR) }\end{array}$ & $\begin{array}{l}\text { 95\% Confidence } \\
\text { Interval (Cl) }\end{array}$ \\
\hline \multicolumn{4}{|l|}{ Video Game Use } \\
\hline Weekly Hours at Wave III & $.023 * *$ & $1.012^{* *}$ & $1.002,1.022$ \\
\hline \multicolumn{4}{|l|}{ Gender (Ref. Male) } \\
\hline Female & $.000 * *$ & $2.771^{* *}$ & $2.121,3.618$ \\
\hline \multicolumn{4}{|l|}{ Race / Ethnicity (Ref. White) } \\
\hline $\begin{array}{l}\text { Black } \\
\text { Latinx } \\
\text { Other }\end{array}$ & $\begin{array}{l}.000^{* *} \\
.006 * * \\
.051 *\end{array}$ & $\begin{array}{c}.363^{* *} \\
.538 * * \\
.651 *\end{array}$ & $\begin{array}{l}.254, .520 \\
.347, .833 \\
.424,1.002\end{array}$ \\
\hline \multicolumn{4}{|c|}{$\begin{array}{l}\text { Education Completed (Ref. Did not } \\
\text { Finish High School) }\end{array}$} \\
\hline $\begin{array}{l}\text { High School Diploma } \\
\text { Bachelors or Higher }\end{array}$ & $\begin{array}{l}.073^{*} \\
.102\end{array}$ & $\begin{array}{l}.776^{*} \\
.705\end{array}$ & $\begin{array}{l}.588,1.024 \\
.463,1.072\end{array}$ \\
\hline \multicolumn{4}{|l|}{ Marriage (Ref. Never Married) } \\
\hline Married at least once & .628 & .943 & $.744,1.195$ \\
\hline
\end{tabular}

Note. ${ }^{* *} p<.05$

${ }^{*} p<.1$ 


\section{Wave IV Cross-Sectional}

Table 21. Logistic Regression of Weekly Hours of Gaming at Wave IV Predicting Having been Diagnosed with Anxiety / Panic Attacks Diagnoses at Wave IV ( $n=3,250)$

\begin{tabular}{|c|c|c|c|}
\hline Variable & $\begin{array}{l}\text { Significance } \\
\text { (p-value) }\end{array}$ & $\begin{array}{l}\text { Adjusted Odds } \\
\text { Ratio } \\
\text { (aOR) }\end{array}$ & $\begin{array}{l}\text { 95\% Confidence } \\
\text { Interval }(\mathrm{Cl})\end{array}$ \\
\hline \multicolumn{4}{|l|}{ Video Game Use } \\
\hline Weekly Hours at Wave IV & $.021 * *$ & $1.014^{* *}$ & $1.002,1.026$ \\
\hline \multicolumn{4}{|l|}{ Gender (Ref. Male) } \\
\hline Female & $.000 * *$ & $2.882 * *$ & $2.271,3.657$ \\
\hline \multicolumn{4}{|l|}{ Race / Ethnicity (Ref. White) } \\
\hline $\begin{array}{l}\text { Black } \\
\text { Latinx } \\
\text { Other }\end{array}$ & $\begin{array}{l}.000^{* *} \\
.005^{* *} \\
.031 * *\end{array}$ & $\begin{array}{l}.349^{* *} \\
.593^{* *} \\
.643^{* *}\end{array}$ & $\begin{array}{l}.252, .482 \\
.413, .853 \\
.431, .960\end{array}$ \\
\hline \multicolumn{4}{|c|}{$\begin{array}{l}\text { Education Completed (Ref. Did not } \\
\text { Finish High School) }\end{array}$} \\
\hline $\begin{array}{l}\text { High School Diploma } \\
\text { Bachelors or Higher }\end{array}$ & $\begin{array}{l}.032 * * \\
.032 * *\end{array}$ & $\begin{array}{l}.765^{* *} \\
.655^{* *}\end{array}$ & $\begin{array}{l}.599, .977 \\
.445, .965\end{array}$ \\
\hline \multicolumn{4}{|l|}{ Marriage (Ref. Never Married) } \\
\hline Married at least once & .242 & .881 & $.713,1.089$ \\
\hline
\end{tabular}

Note. ${ }^{*} p<.05$

$$
{ }^{*} p<.1
$$




\section{Marijuana Use}

\section{Wave III to IV}

Table 22. Logistic Regression of Weekly Hours of Gaming at Wave III Predicting Marijuana Use within the Last 12 Months at Wave IV $(n=2,744)$

\begin{tabular}{|c|c|c|c|}
\hline Variable & $\begin{array}{l}\text { Significance } \\
\text { (p-value) }\end{array}$ & $\begin{array}{l}\text { Adjusted Odds } \\
\text { Ratio } \\
\text { (aOR) }\end{array}$ & $\begin{array}{l}\text { 95\% Confidence } \\
\text { Interval }(\mathrm{Cl})\end{array}$ \\
\hline \multicolumn{4}{|l|}{ Video Game Use } \\
\hline Weekly Hours at Wave III & .778 & 1.001 & $.992,1.010$ \\
\hline \multicolumn{4}{|l|}{ Gender (Ref. Male) } \\
\hline Female & $.000 * *$ & $.547^{* *}$ & $.451, .662$ \\
\hline \multicolumn{4}{|l|}{ Race / Ethnicity (Ref. White) } \\
\hline Black & $.000 * *$ & $.607 * *$ & $.473, .779$ \\
\hline Latinx & .463 & .886 & $.642,1.224$ \\
\hline Other & .478 & .886 & $.634,1.238$ \\
\hline \multicolumn{4}{|c|}{$\begin{array}{l}\text { Education Completed (Ref. Did not } \\
\text { Finish High School) }\end{array}$} \\
\hline $\begin{array}{l}\text { High School Diploma } \\
\text { Bachelors or Higher }\end{array}$ & $\begin{array}{l}.600 \\
.004^{* *}\end{array}$ & $\begin{array}{l}.942 \\
.573^{* *}\end{array}$ & $\begin{array}{l}.753,1.178 \\
.394, .833\end{array}$ \\
\hline \multicolumn{4}{|l|}{ Marriage (Ref. Never Married) } \\
\hline Married at least once & $.000 * *$ & $.367^{* *}$ & $.301, .448$ \\
\hline
\end{tabular}




\section{Wave IV Cross-Sectional}

Table 23. Logistic Regression of Weekly Hours of Gaming at Wave IV Predicting Marijuana Use within the Last 12 Months at Wave IV $(n=3,249)$

\begin{tabular}{|c|c|c|c|}
\hline Variable & $\begin{array}{c}\text { Significance } \\
\text { (p-value) }\end{array}$ & $\begin{array}{l}\text { Adjusted Odds } \\
\text { Ratio } \\
\text { (aOR) }\end{array}$ & $\begin{array}{l}\text { 95\% Confidence } \\
\text { Interval (Cl) }\end{array}$ \\
\hline \multicolumn{4}{|l|}{ Video Game Use } \\
\hline Weekly Hours at Wave IV & $.001 * *$ & $1.015^{* *}$ & $1.006,1.025$ \\
\hline \multicolumn{4}{|l|}{ Gender (Ref. Male) } \\
\hline Female & $.000 * *$ & $.615^{* *}$ & $.516, .732$ \\
\hline \multicolumn{4}{|l|}{ Race / Ethnicity (Ref. White) } \\
\hline Black & $.000 * *$ & $.611^{* *}$ & $.487, .767$ \\
\hline Latinx & .234 & .839 & $.629,1.120$ \\
\hline Other & .357 & .862 & $.628,1.183$ \\
\hline \multicolumn{4}{|c|}{$\begin{array}{l}\text { Education Completed (Ref. Did not } \\
\text { Finish High School) }\end{array}$} \\
\hline $\begin{array}{l}\text { High School Diploma } \\
\text { Bachelors or Higher }\end{array}$ & $\begin{array}{c}.237 \\
.001 * *\end{array}$ & $\begin{array}{l}.886 \\
.552 * *\end{array}$ & $\begin{array}{l}.725,1.083 \\
.391, .779\end{array}$ \\
\hline \multicolumn{4}{|l|}{ Marriage (Ref. Never Married) } \\
\hline Married at least once & $.000 * *$ & $.382 * *$ & $.319, .458$ \\
\hline
\end{tabular}




\section{All Other Drug Use Except Marijuana}

\section{Wave III to IV}

Table 24. Logistic Regression of Weekly Hours of Gaming at Wave III Predicting All Other Drug Use Except Marijuana within the Last 12 Months at Wave IV $(n=2,748)$

\begin{tabular}{|c|c|c|c|}
\hline Variable & $\begin{array}{l}\text { Significance } \\
\text { (p-value) }\end{array}$ & $\begin{array}{l}\text { Adjusted Odds } \\
\text { Ratio } \\
\text { (aOR) }\end{array}$ & $\begin{array}{l}\text { 95\% Confidence } \\
\text { Interval (Cl) }\end{array}$ \\
\hline \multicolumn{4}{|l|}{ Video Game Use } \\
\hline Weekly Hours at Wave III & .758 & 1.001 & $.992,1.011$ \\
\hline \multicolumn{4}{|l|}{ Gender (Ref. Male) } \\
\hline Female & $.000 * *$ & $.605^{* *}$ & $.505, .724$ \\
\hline \multicolumn{4}{|l|}{ Race / Ethnicity (Ref. White) } \\
\hline $\begin{array}{l}\text { Black } \\
\text { Latinx } \\
\text { Other }\end{array}$ & $\begin{array}{l}.000^{* *} \\
.004^{* *} \\
.041^{* *}\end{array}$ & $\begin{array}{l}.105^{* *} \\
.649^{* *} \\
.730^{* *}\end{array}$ & $\begin{array}{l}.074, .148 \\
.485, .868 \\
.541, .987\end{array}$ \\
\hline \multicolumn{4}{|c|}{$\begin{array}{l}\text { Education Completed (Ref. Did not } \\
\text { Finish High School) }\end{array}$} \\
\hline $\begin{array}{l}\text { High School Diploma } \\
\text { Bachelors or Higher }\end{array}$ & $\begin{array}{c}.409 \\
.000 * *\end{array}$ & $\begin{array}{c}.914 \\
.511^{* *}\end{array}$ & $\begin{array}{l}.739,1.131 \\
.362, .723\end{array}$ \\
\hline \multicolumn{4}{|l|}{ Marriage (Ref. Never Married) } \\
\hline Married at least once & $.000 * *$ & $.520 * *$ & $.434, .622$ \\
\hline
\end{tabular}




\section{Wave IV Cross-Sectional}

Table 25. Logistic Regression of Weekly Hours of Gaming at Wave IV Predicting All Other Drug Use Except Marijuana within the Last 12 Months at Wave IV $(n=3,251)$

\begin{tabular}{|c|c|c|c|}
\hline Variable & $\begin{array}{l}\text { Significance } \\
\text { (p-value) }\end{array}$ & $\begin{array}{l}\text { Adjusted Odds } \\
\text { Ratio } \\
\text { (aOR) }\end{array}$ & $\begin{array}{l}\text { 95\% Confidence } \\
\text { Interval }(\mathrm{Cl})\end{array}$ \\
\hline \multicolumn{4}{|l|}{ Video Game Use } \\
\hline Weekly Hours at Wave IV & $.061^{*}$ & 1.009 & $1.000,1.019$ \\
\hline \multicolumn{4}{|l|}{ Gender (Ref. Male) } \\
\hline Female & $.000 * *$ & $.664^{* *}$ & $.563, .782$ \\
\hline \multicolumn{4}{|l|}{ Race / Ethnicity (Ref. White) } \\
\hline $\begin{array}{l}\text { Black } \\
\text { Latinx } \\
\text { Other }\end{array}$ & $\begin{array}{l}.000 * * \\
.000 * * \\
.041 * *\end{array}$ & $\begin{array}{l}.102 * * \\
.599 * * \\
.730 * *\end{array}$ & $\begin{array}{l}.074, .140 \\
.485, .868 \\
.461, .777\end{array}$ \\
\hline \multicolumn{4}{|c|}{$\begin{array}{l}\text { Education Completed (Ref. Did not } \\
\text { Finish High School) }\end{array}$} \\
\hline $\begin{array}{l}\text { High School Diploma } \\
\text { Bachelors or Higher }\end{array}$ & $\begin{array}{l}.095^{*} \\
.000^{* *}\end{array}$ & $\begin{array}{l}.850 * \\
.479 * *\end{array}$ & $\begin{array}{l}.702,1.029 \\
.348, .660\end{array}$ \\
\hline \multicolumn{4}{|l|}{ Marriage (Ref. Never Married) } \\
\hline Married at least once & $.000 * *$ & $.524^{* *}$ & $.445, .618$ \\
\hline
\end{tabular}




\section{CHAPTER V}

\section{Conclusion}

The purpose and objective of this dissertation was to investigate and identify any associations between long term engagement in video game use and various physical, mental, and social health outcomes in a representative sample of youth in the United States as they develop from adolescence to young and early adulthood, utilizing Life Course Theory as an overarching theoretical framework to guide the exploration of the rich data provided by the National Longitudinal Study of Adolescent to Adult Health (Add Health).

An extensive review of the literature helped to identify the selection of three major objectives with potential to make the greatest impact on the field of public health. In addition, the purpose was to fill in gaps that existed in the scientific understanding of the effects of long-term video game use on youth in the United States as they develop from adolescence to young and early adulthood and transition into marriage, parenthood, and occupational careers.

\section{Effects of Life Course Theory Transitional Variables on Levels of Gaming}

Complex samples general linear regression analysis was conducted to test the

effect that life course transitions of entering marriage and parenthood have on the weekly amount of engagement in video game use over time in the sample.

A multiple linear regression was calculated to predict weekly hours of gaming based on having entered marriage and parenthood in both non-gamers and gamers. A 
significant regression equation was found $(\mathrm{F}(2,18059)=52.246, \mathrm{p}<.001$, with an $\mathrm{R} 2$ of 0.076). Participants weekly hours of gaming is equal to $3.939-0.428$ (Parenthood) + 0.942 (Marriage). Participants mean weekly hours of gaming on average decreased 0.942 hours if they reported having ever been married and decreased 0.428 hours if they reported having had a child.

In addition, parallel linear regression analysis was conducted evaluating only those who reported video game use at wave I. A significant regression equation was found for the gamers only group $(\mathrm{F}(2,9300)=15.91, \mathrm{p}<.001$, with an $\mathrm{R} 2$ of 0.058$)$. Participants mean weekly hours of gaming is equal to $6.675-1.175$ (Marriage) $+0.189^{*}$ (parenthood), although the having entered parenthood by itself was not a significant predictor of weekly hours of gaming in the gaming only group. Participants weekly hours of gaming decreased 1.175 hours if they reported having ever been married and increased 0.189 if they reported having ever had a child.

Both marriage and parenthood were significant negative predictors of weekly hours of gaming, concluding that matriculating through these major life transitions plays a role in reducing the amount of video game engagement among persons in the United States as they develop from adolescence to adulthood. 


\section{Prevalence of video game use and gaming disorder}

Analysis of prevalence rates for overall engagement in video game use in the sample revealed lower than expected numbers with almost $60 \%$ of participants reporting no weekly video game use at the time of Wave IV data collection. Previous research has suggested prevalence rates of video game use in the United States to be upwards of $97 \%$ (Lenhart et al., 2008). However, prevalence rates of what are considered problematic or addicted amounts of engagement in weekly video game use was found to be far higher than expected with $65(1.32 \%)$ participants (representing 263,205 persons in the United States) of the total sample reporting engaging in over 30 hours of video game use per week, which accounts for $3.07 \%$ of the sample who reported weekly video game use. These findings suggest that overall video game use among adults in the United States may be lower than previous studies have reported, while among those who do engage in video game use, rates of addicted levels of gaming, which has been identified as 30 or more hours per week, are much higher $(3.07 \%)$ than the approximate $1 \%$ previous research has suggested (Gentile et al., 2017). This highlights an alarming finding with great practical public health significance as this shows that in 2008 , at the time of wave IV data collection, there were over 200,000 persons aged 24-32 in the United States engaging in over 30 hours per week of video game use, which according to current DSM5 guidelines meets qualification for clinical diagnosis of Internet Gaming Disorder (American Psychiatric Association, 2013). 


\section{Implications for Public Health Policy and Practice Implications - Aim 1}

Aim 1 - Evaluate the cross-sectional association between self-reported weekly hours of video game use and the risk for development of metabolic syndrome

Exploration of the data revealed a small yet statistically significant association between weekly hours of video game use and metabolic syndrome severity risk z-score. We don't expect regression analysis models within the behavioral or social sciences to account for all the relevant predictors to explain outcome variables. These results confirm findings from previous studies that there are inherent differences between varying types of sedentary activities. Evidence supports the conclusion that engaging in extended amounts of video game use does contribute to the development of metabolic syndrome risk factors, however it seems to have a smaller effect than other sedentary activities such as television viewing. These findings have great practical significance that show that casual (1 to 7 hours weekly) and even recreational (8 to 30 hours weekly) amounts of video game use may not contribute greatly to the risk for development of metabolic syndrome, but as weekly use gets into the addicted / problematic range (30 hours or more) the cumulative effect of the hours of gaming may be cause for increased risk for development of metabolic syndrome.

Concurrent video game use at Wave IV was shown to be significantly $(\mathrm{p}=.034)$ associated with risk for development of metabolic syndrome at Wave IV. Video game use at Wave I, during adolescence, was marginally significantly associated with the risk of development of metabolic syndrome at Wave IV. These findings indicate that video game use does play a role in the development of metabolic syndrome, however, results showed 
less risk than television viewing. Furthermore, the results from aim 1 demonstrate that other variables such as gender, race, education, and marital status have greater associations with the risk for development of metabolic syndrome than video game use. These findings give support to the argument that inherent differences exist between video game use and television viewing. Future research on the physical effects of video game use should attempt to separate these variables.

\section{Implications - Aim 2}

Aim 2 - Evaluate the longitudinal association between self-reported weekly hours of video game use and measures of violence and aggression

Video game use was not association across any time points of the Add Health dataset with increased measures of violence and aggression. This contributes to wealth of knowledge about video game use and aggression, confirming results of previous studies claiming increased aggression due to video game use has been biased, and likely due to the effects of moral panic theory.

The results from aim 2 demonstrate that demographic components such as gender and race / ethnicity in conjunction with Life Course Theory variables of education status and marital status play a major role in predicting overall measures of violence and aggression. Female participants were shown to be half as likely as their male counterparts to indicate previous exposure to violence and aggression. Participants who reported earning a high school diploma were half as likely those who did not graduate to indicate previous exposure to violence and aggression, and those with a bachelor's degree or 
higher were more than 5 times less likely to report exposure to violence and aggression as compared to those who did not graduate.

\section{Implications - Aim 3}

Aim 3 - Evaluate the longitudinal association between self-reported weekly hours of video game use and various mental health outcomes

Engagement in video game use over time was shown to be associated with sleep problems, depression, anxiety / panic attacks, and marijuana use. No association was found between video game use and attention deficit disorder / attention deficit hyperactivity disorder and all other drug use except marijuana. Across all dependent variables, gender, race / ethnicity, education status, and marital status displayed more significant and greater associations than video game use. In addition to the previous aims, this confirms the currently held paradigm within public health of the major effects the social determinants of health play on measurable health related outcomes of young adults in the United States.

\section{Discussion}

Through the work of this dissertation several benefits and risks of engaging in video game use have been identified, helping to inform future public health practice and research in several ways. In moderation video game use was shown to have prosocial and 
positive effects on youth development as they grow into adulthood, including reducing the reported amount of marijuana use among participants.

However, when video game use exceeds 30 hours or more per week, detrimental effects begin to emerge, including an increased risk for the development of metabolic syndrome and sleep problems, depression, ADD/ADHD, and anxiety.

In addition, we concluded that transitioning through various major Life Course Theory trajectories of entering marriage and parenthood reduced the incidence of video game use across all groups, genders, and races/ethnicities. This finding has great implications for the development of future interventions, as they can target intervention strategies towards individuals who engage in high amounts of video game use and are unmarried and childless.

Several limiting factors potentially biasing the findings of this dissertation have been highlighted.

Firstly, The diagnostic criteria for Internet Gaming Disorder included nine categories: Preoccupation with internet games; Withdrawal symptoms when internet gaming is taken away; Tolerance with internet game play; Unsuccessful attempts to reduce or control internet gaming; Loss of interest in other hobbies or entertainment; Continued excessive use despite psychosocial problems ;Underreports or deceives others regarding their internet gaming use; Uses internet games as a form of escapism from negative affective states or emotions; Has jeopardized social relationships, occupations, or their education because of internet gaming (American Psychological Association DSM-5, 2013) However, this study used only 30 hours of gaming as a cutoff for 
examining health outcomes of the addicted gaming level group instead of the criteria listed above.

Information bias on the self-reported number of weekly hours of video game use raises another limitation. There was no way to avoid this as self-reporting is the most common approach for gathering epidemiologic and medical research (Althubaiti, 2016). However, this presents several limitations to the interpretation and generalizability of the findings. Firstly, this creates social desirability bias, in which participants are more likely to give responses they deem as more socially desirable; for example, in this case, a participant may feel embarrassed or ashamed of the number of weekly hours of video game use they are engaging in and give responses that underestimate the actual number of hours. Ensuring anonymity of responses can assist in overcoming social desirability bias, however, cannot completely account for bias in participants responses. Secondly, self-reporting is subject to recall bias in which study participants erroneously estimate responses to questions based on things that happened previously. Since participants may be unlikely to log their engagement in weekly hours of video game use, they may have difficulty recalling the true number of hours they engaged in over the past week. A potential solution to recall bias is to minimize the amount of time that participants may be asked to recall, for example asking about video game use in the past week, as opposed to over the past month or year.

Another major limitation of this study was the failure to fulfill the conditional independence assumption summary, which assumes that there are no confounding variables related to weekly hours of gaming omitted from the analysis. However, there 
was no way of knowing specific details about the differing content of video games that the sample was engaging in, for example, there was no way to know if an individual was primarily engaging in violent video games, which previous research has suggested would play a major role in the outcome variables investigated by this dissertation.

An additional limiting factor is the decile reporting of Triglycerides and HDL in wave IV biomarker data. Add Health Wave IV data reports the total triglyceride and HDL levels as decile values. Therefore, to calculate metabolic syndrome severity risk zscores, upper end of average range of values for the sample was used to estimate actual total triglyceride and HDL decile values for in the metabolic syndrome severity z-score calculation. Furthermore, no biomarker data was recorded in the data collection phases of Add Health waves I, II, and III to allow for longitudinal analysis of the Wave IV biomarker data.

\section{Recommendations}

Wave III mean hours of gaming were similar (4.526 and 4.788 respectively) in both the gaming and non-gaming groups (reported zero hours of gaming during waves I or II). The gaming group had higher mean hours of gaming across all other time points. This finding is of great practical significance, indicating at the time of wave III data collection, when participants were transitioning through young adulthood (age 18 to 26), they reported similar levels of gaming regardless of the amount of gaming during their youth. However, as they continued to develop into adulthood, we see at the time of wave IV data collection (ages 32 to 42) the gaming group continue to trend upward, while the 
non-gaming group began trending downward. This highlights the persistent effect that gaming during adolescence has on individuals in the United States as they develop into adulthood. Future researchers should explore and investigate the mechanisms of video game use behavior at these crucial time points in both adolescents and young adulthood.

In addition, this dissertation recommends the utilization of usage limits to potentially decrease the risk of negative long-term outcomes such as increased risk for the development of metabolic syndrome and increased risk of aggression in female gamers. A successful example of usage limits in other regions is the restriction placed on video game use by the Chinese government for online games including limits built into gaming software by publishers and implemented an age restriction of 16 years old for attending public internet locations (Rooij et al., 2010). Furthermore, due to the finding of several negative outcomes of engaging in more than 30 hours per week of video game use, companies who develop and publish video games should set time limits within the software to regulate and limit daily use, that would prevent individuals from using the product more than the recommended hours per day.

Additionally, future research should attempt to replicating the findings of the current dissertation utilizing Add Health wave V biomarker data once made available to confirm findings and evaluate continuing or changing trends over time on the effect of video game use on the development of risk for metabolic syndrome. Subsequently, future researchers should continue to investigate inherent differences between casual, recreational, and addicted level gaming among persons living in the United States, as this 
study has shown there may be more addicted gamers in the United States than previous studies had concluded.

Also, future research should investigate gender differences in video game use and health outcomes. To understand why female video game users tend to display lower levels of video game addiction and reported higher scores of overall measures of violence and aggression, than their male counterparts.

Lastly, future research should further investigate the association between video game use and drug use, to explore how concurrent video game use plays a role in increasing amounts of marijuana and other drug use. 


\section{LIST OF REFERENCES}

Adachi, P. J. C., \& Willoughby, T. (2011). The effect of video game competition and violence on aggressive behavior: Which characteristic has the greatest influence? Psychology of Violence, 1(4), 259-274. doi: 10.1037/a0024908

Adachi, P., \& Willoughby, T. (2012). The Effect of Video Game Competition and Violence on Aggressive Behavior. PsycEXTRA Dataset. doi: 10.1037/e630282012001

Adachi, P. J. C., \& Willoughby, T. (2017). The Link Between Playing Video Games and Positive Youth Outcomes. Child Development Perspectives, 11(3), 202-206. doi: 10.1111/cdep.12232

Alberti, K. G. M. M., Zimmet, P., \& Shaw, J. (2006). Metabolic syndrome-a new worldwide definition. A Consensus Statement from the International Diabetes Federation. Diabetic Medicine, 23(5), 469-480. doi: 10.1111/j.14645491.2006.01858.x

Althubaiti, A. (2016). Information bias in health research: definition, pitfalls, and adjustment methods. Journal of Multidisciplinary Healthcare, 211. doi: 10.2147/jmdh.s104807

Amstadter, A. B., Broman-Fulks, J., Zinzow, H., Ruggiero, K. J., \& Cercone, J. (2009). Internet-based interventions for traumatic stress-related mental health problems: A review and suggestion for future research. Clinical Psychology Review, 29(5), 410420. doi: 10.1016/j.cpr.2009.04.001

Anderson, C. A., \& Bushman, B. J. (2019). Effects of Violent Video Games on Aggressive Behavior, Aggressive Cognition, Aggressive Affect, Physiological Arousal, and Prosocial Behavior: A Meta-Analytic Review of the Scientific Literature. PsycEXTRA Dataset. doi: 10.1037/e315012004-001

Bean, A. M., Nielsen, R. K. L., Rooij, A. J. V., \& Ferguson, C. J. (2017). Video game addiction: The push to pathologize video games. Professional Psychology: Research and Practice, 48(5), 378-389. doi: 10.1037/pro0000150

Berzin, S. C. (2010). Educational Aspirations among Low-Income Youths: Examining Multiple Conceptual Models. Children \& Schools, 32(2), 112-124. doi:

$10.1093 / \mathrm{cs} / 32.2 .112$ 
Birkland, T. A., \& Lawrence, R. G. (2009). Media Framing and Policy Change After Columbine. American Behavioral Scientist, 52(10), 1405-1425. doi: $10.1177 / 0002764209332555$

Casiano, H., Kinley, J., Katz, L., Chartier, M., \& Sareen, J. (2012). Media Use and Health Outcomes in Adolescents: Findings from a Nationally Representative Survey. Journal of the Canadian Academy of Child and Adolescent Psychiatry, 21(4), 296301.

Chyi, H. I., \& Mccombs, M. (2004). Media Salience and the Process of Framing: Coverage of the Columbine School Shootings. Journalism \& Mass Communication Quarterly, 81(1), 22-35. doi: 10.1177/107769900408100103

Cohen, S. (1973). Folk devils and moral panics the creation of the Mods and Rockers. London: MacGibbon \& Kee.

Cohen, S. (2011). Whose side were we on? The undeclared politics of moral panic theory. Crime, Media, Culture: An International Journal, 7(3), 237-243. doi: $10.1177 / 1741659011417603$

Cunningham, S., Engelstätter, B., \& Ward, M. R. (2011). Understanding the Effects of Violent Video Games on Violent Crime. SSRN Electronic Journal. doi: $10.2139 / \mathrm{ssrn} .1886419$

Dannefer, D. (2003). Cumulative Advantage/Disadvantage and the Life Course: CrossFertilizing Age and Social Science Theory. The Journals of Gerontology Series B: Psychological Sciences and Social Sciences, 58(6). doi: 10.1093/geronb/58.6.s327

Decamp, W., \& Ferguson, C. J. (2017). The Impact of Degree of Exposure to Violent Video Games, Family Background, and Other Factors on Youth Violence. Journal of Youth and Adolescence, 46(2), 388-400. doi: 10.1007/s10964-016-0561-8

Deflem, M. (2019). Popular Culture and Social Control: The Moral Panic on Music Labeling. American Journal of Criminal Justice. doi: 10.1007/s12103-019-09495-3

Devís-Devís, J., Peiró-Velert, C., Beltrán-Carrillo, V. J., \& Tomás, J. M. (2012). Brief report: Association between socio-demographic factors, screen media usage and physical activity by type of day in Spanish adolescents. Journal of Adolescence, 35(1), 213-218. doi: 10.1016/j.adolescence.2010.11.009

Drummond, A., \& Sauer, J. D. (2014). Video-Games Do Not Negatively Impact Adolescent Academic Performance in Science, Mathematics or Reading. PLoS ONE, 9(4). doi: 10.1371/journal.pone.0087943 
Ekelund, U., Luan, J., Sherar, L. B., Esliger, D. W., Griew, P., \& Cooper, A (2012). Moderate to Vigorous Physical Activity and Sedentary Time and Cardiometabolic Risk Factors in Children and Adolescents. Journal of the American Medical Association, 307(7), 704. doi: 10.1001/jama.2012.156

Elder, G. H. (1998). The Life Course as Developmental Theory. Child Development, 69(1), 1-12. doi: 10.1111/j.1467-8624.1998.tb06128.x

Elder, G. H. (2018). Children of the great depression: social change in life experience. Routledge.

Evans, B. C., Crogan, N., Belyea, M., \& Coon, D. (2008). Utility of the Life Course Perspective in Research with Mexican American Caregivers of Older Adults. Journal of Transcultural Nursing, 20(1), 5-14. doi: $10.1177 / 1043659608325847$

Ferguson, C. J. (2015). Clinicians' attitudes toward video games vary as a function of age, gender and negative beliefs about youth: A sociology of media research approach. Computers in Human Behavior, 52, 379-386. doi: 10.1016/j.chb.2015.06.016

Ferguson, C. J. (2015). Do Angry Birds Make for Angry Children? A MetaAnalysis. PsycEXTRA Dataset. doi: 10.1037/e598722013-001

Ferguson, C. J., \& Colwell, J. (2017). Understanding Why Scholars Hold Different Views on the Influences of Video Games on Public Health. Journal of Communication, 67(3), 305-327. doi: 10.1111/jcom.12293

Gentile, D. A., Lynch, P. J., Linder, J. R., \& Walsh, D. A. (2004). The effects of violent video game habits on adolescent hostility, aggressive behaviors, and school performance. Journal of Adolescence, 27(1), 5-22. doi:

10.1016/j.adolescence.2003.10.002

Gentile, D. A., \& Gentile, J. R. (2008). Violent Video Games as Exemplary Teachers: A Conceptual Analysis. Journal of Youth and Adolescence, 37(2), 127-141. doi: 10.1007/s10964-007-9206-2

Gentile, D. A. (2009). Pathological Video-Game Use Among Youth Ages 8 to 18. Psychological Science, 20(5), 594-602. doi: 10.1111/j.1467-9280.2009.02340.x

Gentile, D. A., Anderson, C. A., Yukawa, S., Ihori, N., Saleem, M., Ming, L. K. \&, Sakamoto, A. (2009). The Effects of Prosocial Video Games on Prosocial Behaviors: International Evidence From Correlational, Longitudinal, and Experimental Studies. Personality and Social Psychology Bulletin, 35(6), 752-763. doi: $10.1177 / 0146167209333045$ 
Gentile, D. A., Choo, H., Liau, A., Sim, T., Li, D., Fung, D., \& Khoo, A. (2011). Pathological Video Game Use Among Youths: A Two-Year Longitudinal Study. Pediatrics, 127(2). doi: 10.1542/peds.2010-1353

George, L. K. (2015). Handbook of aging and the social sciences. Amsterdam: Academic Press.

Goldfield, G. S., Kenny, G. P., Hadjiyannakis, S., Phillips, P., Alberga, A. S., Saunders, T. J., ... Sigal, R. J. (2011). Video Game Playing Is Independently Associated with Blood Pressure and Lipids in Overweight and Obese Adolescents. PLoS ONE, 6(11). doi: 10.1371/journal.pone.0026643

Granic, I., Lobel, A., \& Engels, R. C. M. E. (2014). The Benefits of Playing Video Games. American Psychologist 69(1), 66-78. https://doi.org/10.1037/a0034857

Harris, K. M., Gordon-Larsen, P., Chantala, K., \& Udry, J. R. (2006). Longitudinal Trends in Race/Ethnic Disparities in Leading Health Indicators From Adolescence to Young Adulthood. Archives of Pediatrics \& Adolescent Medicine, 160(1), 74. doi: 10.1001/archpedi.160.1.74

Harris, K. M. (2013). The Add Health Study: Design and Accomplishments. University of North Carolina at Chapel Hill. 1-22.

Isomaa, B., Almgren, P., Tuomi, T., Forsen, B., Lahti, K., Nissen, M., ... Groop, L. (2001). Cardiovascular Morbidity and Mortality Associated with the Metabolic Syndrome. Diabetes Care, 24(4), 683-689. doi: 10.2337/diacare.24.4.683

Kelley C., \& Peterson, J. (1997) Add Health Program Project Manual

King, D. L., Delfabbro, P. H., \& King, D. L. (2016). The Cognitive Psychopathology of Internet Gaming Disorder in Adolescence. Journal of Abnormal Child Psychology, 1635-1645. https://doi.org/10.1007/s10802-016-0135-y

Kovess-Masfety, V., Keyes, K., Hamilton, A., Hanson, G., Bitfoi, A., \& Golitz, D., (2016). Is time spent playing video games associated with mental health, cognitive and social skills in young children? Social Psychiatry and Psychiatric Epidemiology, 51(3), 349-357. doi: 10.1007/s00127-016-1179-6

Kuss, D. J., Griffiths, M. D., \& Pontes, H. M. (2017). DSM-5 diagnosis of Internet Gaming Disorder: Some ways forward in overcoming issues and concerns in the gaming studies field. Journal of Behavioral Addictions, 6(2), 133-141. doi: 10.1556/2006.6.2017.032

Lenhart, A., \& Kahne, J. (2008). Teens, Video Games, and Civics. Pew Research, 9(16) 
Marshall, S. J., Biddle, S. J. H., Gorely, T., Cameron, N., \& Murdey, I. (2004).

Relationships between media use, body fatness and physical activity in children and youth: a meta-analysis. International Journal of Obesity, 28(10), 1238-1246. doi: 10.1038/sj.ijo.0802706

Meyers, K. S. (2002). Television and video game violence: age differences and the combined effects of passive and interactive violent media. LSU Doctoral Dissertations, 2214. https://digitalcommons.lsu.edu/gradschool_dissertations/2214

Motl, R. W., Mcauley, E., Birnbaum, A. S., \& Lytle, L. A. (2006). Naturally occurring changes in time spent watching television are inversely related to frequency of physical activity during early adolescence. Journal of Adolescence, 29(1), 19-32. doi: 10.1016/j.adolescence.2005.01.005

Mozaffarian, D., Kamineni, A., Prineas, R. J., \& Siscovick, D. S. (2008). Metabolic Syndrome and Mortality in Older Adults. Archives of Internal Medicine, 168(9), 969. doi: 10.1001/archinte.168.9.969

Panahi, S., \& Tremblay, A. (2018). Sedentariness and Health: Is Sedentary Behavior More Than Just Physical Inactivity? Frontiers in Public Health, 6. doi: 10.3389/fpubh.2018.00258

Petry, N. M., \& Obrien, C. P. (2013). Internet gaming disorder and the DSM5. Addiction, 108(7), 1186-1187. doi: 10.1111/add.12162

Pomeroy, B. R. (2012). Video Games or TV: Which is Worse? Real Clear Science (7) 810.

Przybylski, A. K., Ryan, R. M., \& Rigby, C. S. (2009). The Motivating Role of Violence in Video Games. Personality and Social Psychology Bulletin, 35(2), 243-259. doi: $10.1177 / 0146167208327216$

Radford, T. (2000). Computer games linked to violence. The Guardian 93

Rooij, A. J. V., Meerkerk, G.-J., Schoenmakers, T. M., Griffiths, M., \& Mheen, D. V. D. (2010). Video game addiction and social responsibility. Addiction Research \& Theory, 18(5), 489-493. doi: 10.3109/16066350903168579

Rosser, J. C., Xinwei, J., Charles, L., Katherine, J., Choi, M., Jalink, M. B., \& Hoedemaker, C. (2017). Impact of Super Monkey Ball and Underground video games on basic and advanced laparoscopic skill training. Surgical Endoscopy, 31(4), 1544-1549. https://doi.org/10.1007/s00464-016-5059-7 
Ryan, R. M., Rigby, C. S., \& Przybylski, A. (2006). The Motivational Pull of Video Games: A Self-Determination Theory Approach. Motivation and Emotion, 30(4), 344-360. doi: 10.1007/s11031-006-9051-8

Shanahan, M. J. (2000). Pathways to Adulthood in Changing Societies: Variability and Mechanisms in Life Course Perspective. Annual Review of Sociology, 26(1), 667692. doi: 10.1146/annurev.soc.26.1.667

Thorne, H. T., Smith, J. J., Morgan, P. J., Babic, M. J., \& Lubans, D. R. (2014). Video game genre preference, physical activity and screen-time in adolescent boys from low-income communities. Journal of Adolescence, 37(8), 1345-1352. https://doi.org/10.1016/j.adolescence.2014.09.012

Trisolini, D. C., Petilli, M. A., \& Daini, R. (2018). Is action video gaming related to sustained attention of adolescents? Quarterly Journal of Experimental Psychology, 71(5), 1033-1039. doi: 10.1080/17470218.2017.1310912

Weesner, B. J. (2007). On Game Design: A History of Video Games, Game Career Guide 1-15.

Willoughby, T. (2008). A short-term longitudinal study of Internet and computer game use by adolescent boys and girls: Prevalence, frequency of use, and psychosocial predictors. Developmental Psychology, 44(1), 195-204. doi: 10.1037/00121649.44.1.195

Willoughby, T., Adachi, P. J. C., \& Good, M. (2012). A longitudinal study of the association between violent video game play and aggression among adolescents. Developmental Psychology, 48(4), 1044-1057. doi: 10.1037/a0026046 


\section{Appendix}

W3 H3DA5 On the average, how many hours a week do you spend playing video or computer games, or using a computer for something other than school work? Response Value Response Label Frequency Percent

$0 \quad 0$ hours $5207 \quad 34.26$

1-168 range 1 to 168 hours $9896 \quad 65.13$

996 refused $30 \quad 0.20$

$998 \quad$ don't know $53 \quad 0.35$

999 not applicable $11 \quad 0.07$

W4 H4DA23 In the past seven days, how many hours did you spend playing video or computer games, or using a computer? Do not count internet use for work or school.

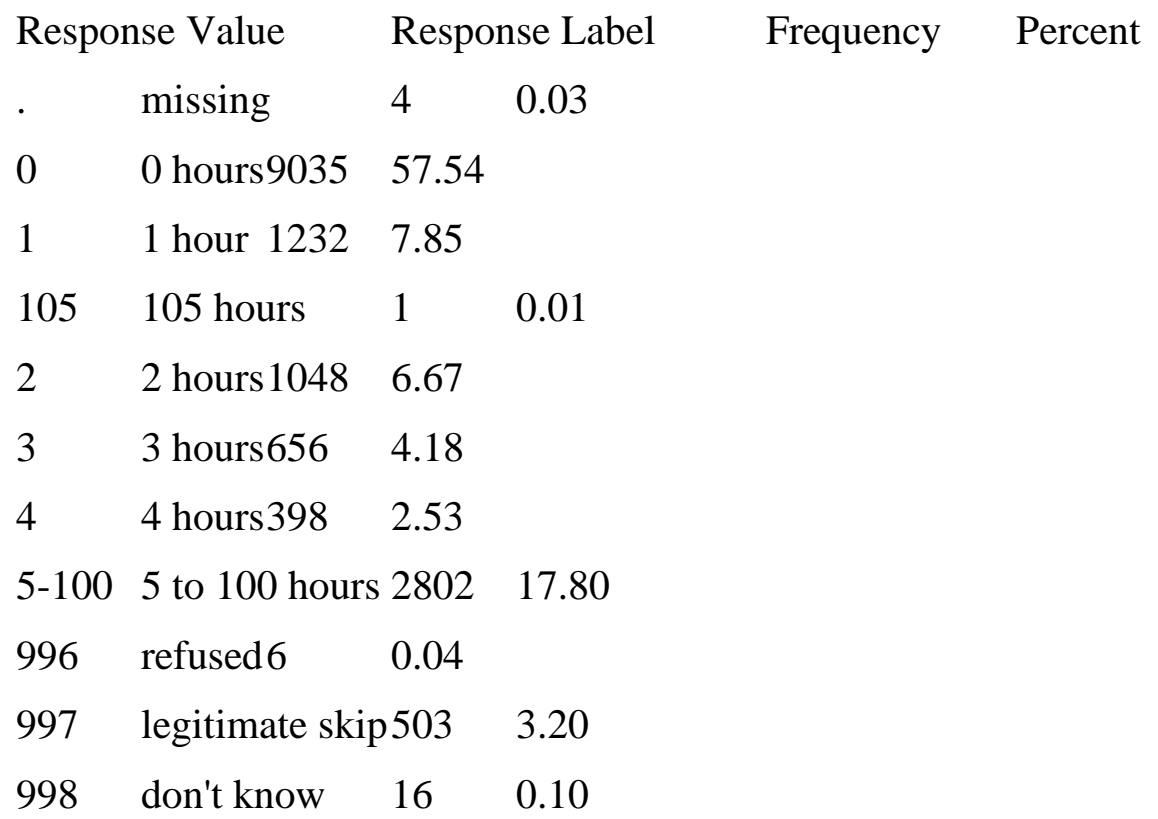

W4 H4SP5 Over the past four weeks, how often did you have trouble falling asleep?

Response Value Response Label Frequency Percent

$0 \quad$ never in the past four weeks 7352 
1 less than once a week 2925

18.63

21 or 2 times a week 2773

17.66

33 or 4 times a week 1258

8.01

45 or more times a week

$5 \quad$ not asked in pretest 193

\section{Instrument Variable Question Text Response Data}

W4 H4SP6 Over the past four weeks, how often did you have trouble staying asleep through the night? For example, you woke up several times at night or woke up earlier than you planned to?

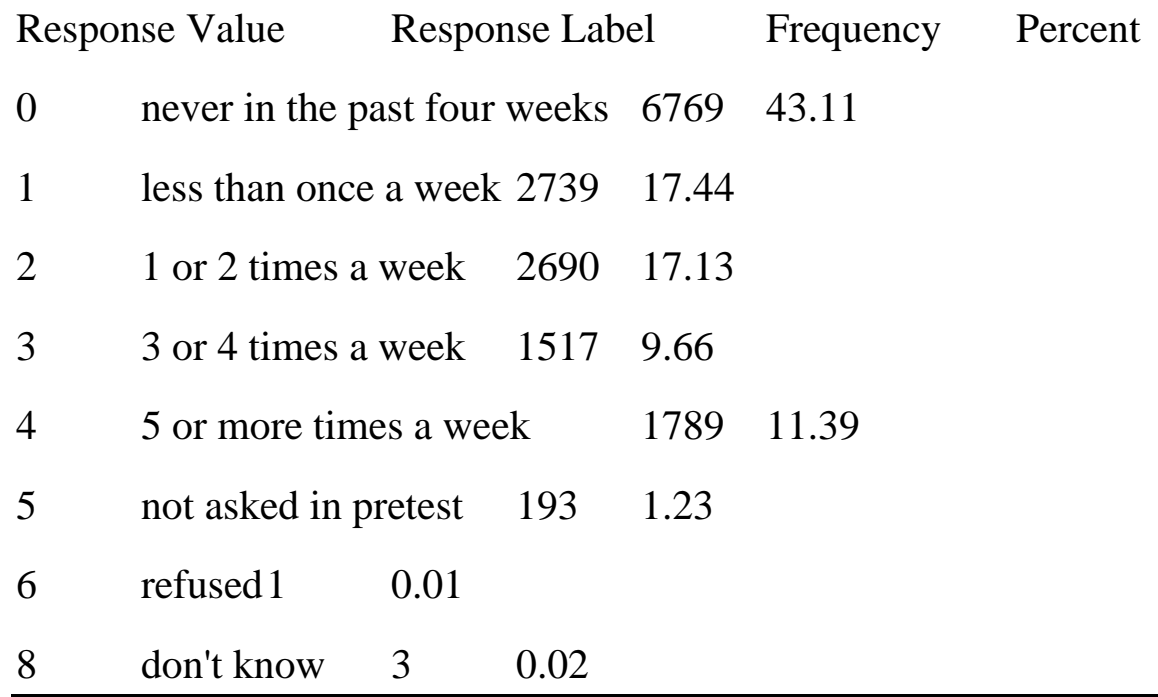

W1, and W2 S60J In the last month, how often did you have trouble falling asleep or staying asleep?

Response Value Response Label Frequency Percent

\begin{tabular}{|c|c|c|c|}
\hline & missing & 7387 & 8.20 \\
\hline 0 & never 35773 & 39.70 & \\
\hline 1 & rarely 21131 & 23.45 & \\
\hline 2 & occasionally & 13141 & 14.58 \\
\hline & often 8482 & 9.41 & \\
\hline
\end{tabular}


$4 \quad$ everyday $\quad 4106 \quad 4.56$

$9 \quad$ multiple response $\quad 98 \quad 0.11$

Instrument Variable Question Text Response Data

W4 H4ID5L Has a doctor, nurse or other health care provider ever told you that you have or had: attention problems or ADD or ADHD?

Response Value Response Label Frequency Percent

$0 \quad$ no $\quad 1492495.05$

$1 \quad$ yes $\quad 775 \quad 4.94$

$6 \quad$ refused $2 \quad 0.01$

W4 H4ID5H Has a doctor, nurse or other health care provider ever told you that you have or had: depression?

Response Value Response Label Frequency Percent

$0 \quad$ no 1329284.66

$1 \quad$ yes $2406 \quad 15.32$

$6 \quad$ refused $2 \quad 0.01$

$8 \quad$ don't know $\quad 1 \quad 0.01$

Instrument Variable Question Text Response Data

W4 H4ID5I Has a doctor, nurse or other health care provider ever told you that you have or had: post-traumatic stress disorder or PTSD?

Response Value Response Label Frequency Percent

$0 \quad$ no $\quad 1524597.10$

$1 \quad$ yes $\quad 453 \quad 2.89$

$6 \quad$ refused $3 \quad 0.02$ 


\section{Instrument Variable Question Text Response Data}

W4 H4TO70 During the past 12 months, on how many days did you use marijuana?

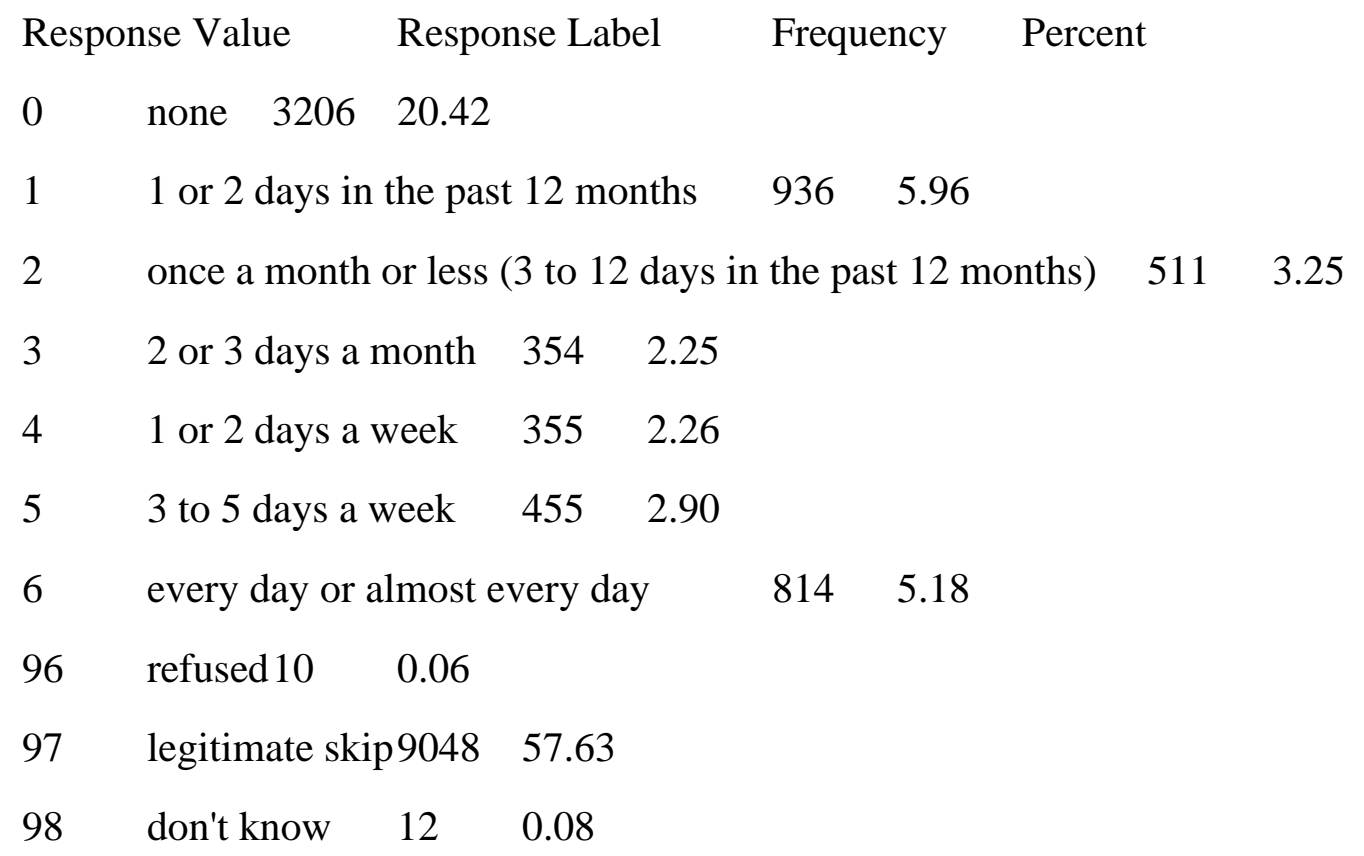

Instrument Variable Question Text Response Data

W4 H4TO70 During the past 12 months, on how many days did you use marijuana?

\begin{tabular}{|c|c|c|c|c|c|c|c|c|c|c|}
\hline \multicolumn{3}{|c|}{ Response Value } & \multicolumn{3}{|c|}{ Response Label } & \multicolumn{2}{|c|}{ Frequency } & \multicolumn{2}{|c|}{ Percent } & \\
\hline 0 & none & 3206 & 20.42 & & & & & & & \\
\hline 1 & 1 or 2 & days il & the pas & $12 \mathrm{~m}$ & nths & 936 & 5.96 & & & \\
\hline 2 & once a & montl & or less & 3 to 1 & days & the $p$ & t $12 \mathrm{r}$ & onths) & 511 & 3.25 \\
\hline 3 & 2 or 3 & days a & nonth & 354 & 2.25 & & & & & \\
\hline 4 & 1 or 2 & days a & veek & 355 & 2.26 & & & & & \\
\hline 5 & 3 to 5 & days a & veek & 455 & 2.90 & & & & & \\
\hline 6 & every & day or & lmost & very c & & 814 & 5.18 & & & \\
\hline 96 & refuse & $\mathrm{d} 10$ & 0.06 & & & & & & & \\
\hline 97 & legitin & late sk & م9048 & 57.6 & & & & & & \\
\hline 98 & don't 1 & now & 12 & 0.08 & & & & & & \\
\hline
\end{tabular}




\section{Instrument Variable Question Text Response Data}

W4 H4ID5J Has a doctor, nurse or other health care provider ever told you that you have or had: anxiety or panic disorder?

\begin{tabular}{llllll}
\multicolumn{2}{l}{ Response Value } & Response Label & Frequency & Percent \\
0 & no & 13872 & 88.35 & \\
1 & yes & 1827 & 11.64 & \\
6 & refused 2 & & \\
\hline
\end{tabular}

W4 H4TR9 Thinking about all the relationships and sexual encounters you have ever had, (how many times have you ever been pregnant/how many times have you ever made a partner pregnant)? Include all pregnancies, whether they resulted in babies born alive, stillbirth, abortion, miscarriage, or ectopic or tubal pregnancy. [If H4TR7=Yes]: Be sure to include your current pregnancy in your count.

Response Value Response Label Frequency Percent

$0 \quad 0$ pregnancies $6113 \quad 38.93$

$1 \quad 1$ pregnancy $3168 \quad 20.18$

$17 \quad 17$ pregnancies $\quad 1 \quad 0.01$

$18 \quad 18$ pregnancies $\quad 2 \quad 0.01$

1919 pregnancies $\quad 1 \quad 0.01$

$2 \quad 2$ pregnancies $2935 \quad 18.69$

$3 \quad 3$ pregnancies $1786 \quad 11.38$

$4 \quad 4$ pregnancies $909 \quad 5.79$

5-15 5 to 15 pregnancies $725 \quad 5.00$

96 refused $49 \quad 0.31$

98 don't know $12 \quad 0.08$ 
W4 H4TR1 How many persons have you ever married? Be sure to include your current spouse if you are married now.

\begin{tabular}{llllll}
\multicolumn{2}{c}{ Response Value } & \multicolumn{2}{c}{ Response Label } & Frequency & Percent \\
0 & 0 persons & 7885 & 50.22 & \\
1 & 1 person & 7169 & 45.66 \\
2 & 2 persons & 597 & 3.80 \\
3 & 3 persons & 29 & 0.18 \\
4 & 4 persons & 2 & 0.01 \\
6 & refused 16 & 0.10 & \\
8 & don't know & 3 & 0.02
\end{tabular}


VITA

\section{ARI DANIEL HOZMAN}

Born, Long Beach, California

2006-2010

A.A., Liberal Arts

College of the Desert

Palm Desert, California

2010-2012

B.S., Kinesiology; Exercise Science

California State University San Bernardino

San Bernardino, California

2012-2014

M.S., Exercise Physiology

San Diego State University

San Diego, California

$2015-2020$

Doctoral Candidate

Florida International University

Miami, Florida

$2015-2016$

Research Assistant

Florida International University

Miami, Florida

$2016-2017$

$2018-2019$

Graduate Assistant Professor

Florida International University

Miami, Florida

2019-2020

Dissertation Year Fellowship Award

Florida International University

Miami, Florida 


\section{PUBLICATIONS AND PRESENTATIONS}

Ari Hozman, Chintan Bhatt, Jessica Weissman, William Darrow. Major Health Disparities in Food Security in Miami-Dade County. American Public Health Association. Annual Meeting and Expo. November 2016. Denver, CO

Ari Hozman, Zachary Clayton, Brittany Braden, Mark Kern. Glutamine enhances plasma glutamine and maintains concentrations of alanine and arginine following high intensity cycling. American College of Sports Medicine. Annual Meeting. May 2017. Denver, CO

Ari Hozman, Ramandeep Kaur, Elena Bastida. Factors influencing participation in community-based lifestyle modification program among Mexican-American participants. American Public Health Association. Annual Meeting and Expo. November 2018. San Diego, CA

Ari Hozman. Enhanced Text-messaging to Increase Motivation to Exercise. Graduate Student Appreciation Week at FIU. March 2018. Miami, FL.

Zachary Clayton, Ari Hozman, Brittany Braden, and Mark Kern. (2017) L-glutamine Enhances Plasma Glutamine and Maintains Concentrations of Alanine and Arginine Following High Intensity Cycling Medicine \& Science in Sports \& Exercise 5S: 318. 